Applied Physiology, Nutrition, and Metabolism

Canadian

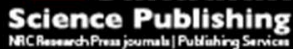
Physiologie appliquée, nutrition et métabolisme

\title{
Regulation of Skeletal Muscle Capillary Growth in Exercise and Disease
}

\begin{tabular}{|r|l|}
\hline Journal: & Applied Physiology, Nutrition, and Metabolism \\
\hline Manuscript ID & apnm-2015-0336.R1 \\
\hline Manuscript Type: & Award Lecture \\
\hline Date Submitted by the Author: & 31-Aug-2015 \\
\hline Complete List of Authors: & $\begin{array}{l}\text { Haas, Tara; York University, } \\
\text { Nwadozi, Emmanuel; York University, }\end{array}$ \\
\hline Keyword: & hypoxia, blood flow, growth factors, peripheral artery disease, diabetes \\
\hline
\end{tabular}


1

2

3

4

5

6 Short Title: Skeletal muscle angiogenesis

7

$8{ }^{*}$ Address for Correspondence:

9 Tara Haas, PhD

10 Angiogenesis Research Group

11 York University

12 Rm. 341 Farquharson Building

134700 Keele St.

14 Toronto, ON

15 M3J 1 P3 Canada

16 Phone: (416) 736-2100 x77313

17 Email: thaas@yorku.ca
Tara L. Haas ${ }^{*}$ and Emmanuel Nwadozi

York University, Toronto, ON

18

19

20 


\section{Abstract:}

22 Capillaries, which are the smallest and most abundant type of blood vessel, form the primary

23 site of gas, nutrient and waste transfer between the vascular and tissue compartments.

24 Skeletal muscle exhibits the capacity to generate new capillaries (angiogenesis) as an

25 adaptation to exercise training, thus ensuring that the heightened metabolic demand of the

26 active muscle is matched by an improved capacity for distribution of gases, nutrients and waste

27 products. This review summarizes the current understanding of the regulation of skeletal

28 muscle capillary growth. The multi-step process of angiogenesis is co-ordinated through the

29 integration of a diverse array of signals associated with hypoxic, metabolic, hemodynamic and

30 mechanical stresses within the active muscle. The contributions of metabolic and mechanical

31 factors to the modulation of key pro- and anti- angiogenic molecules are discussed within the

32 context of responses to a single aerobic exercise bout, short term and long term training.

33 Finally, the paradoxical lack of angiogenesis in peripheral artery disease and diabetes, and the

34 implications for disease progression and muscle health are discussed. Future studies that

35 emphasize an integrated analysis of the mechanisms that control skeletal muscle capillary

36 growth will enable development of targeted exercise programs that effectively promote

37 angiogenesis in healthy individuals and in patient populations.

38 Keywords: Hypoxia; Blood Flow; Growth Factors; Peripheral artery disease; Diabetes 


\section{Structure and function of capillaries}

42 Capillaries form the smallest unit of the vasculature, with an average diameter of $\sim 5 \mu \mathrm{m}$. It is estimated that capillaries comprise $2-3 \%$ of the skeletal muscle mass. For the past century, it has been recognized that a very tight relationship exists between the capillary and the myofibre. Within skeletal muscle, capillaries are oriented longitudinally in parallel with the myofibres, with short interconnecting capillaries that form looping networks (Fig.1). The intimate proximity of capillaries to the myofibres, together with morphological features of the capillary that favour efficient trans-capillary diffusion (endothelial cell thickness of $0.2 \mu \mathrm{m}$ in non-nuclear regions) establish the capillary as the critical site of nutrient and gas exchange and waste removal (Bruns and Palade 1968; Simionescu et al. 1974). The capillary network also plays a significant role in establishing skeletal muscle insulin sensitivity through controlling the transfer of plasma insulin to the surrounding myocytes (Azizi et al. 2015; Barrett et al. 2009; Lillioja et al. 1987; Stanford and Goodyear 2014). August Krogh first modeled the oxygen exchange properties of the skeletal muscle capillary network. By relating skeletal muscle capillary density to the metabolic rate of a broad variety of animals, he estimated the tissue volume that could receive a sufficient amount of oxygen from an individual capillary (Krogh

Another substantial advancement in this field of research occurred with the recognition that 1919). His work made the seminal contribution in recognizing that the number and distribution of capillaries establishes the oxygenation and, consequently, the metabolic potential of the surrounding skeletal myocytes. Romanul (1964) provided evidence that the number of capillaries surrounding a muscle fiber correlates positively with the fiber's oxidative metabolic potential. Efforts made to map the architecture of the skeletal muscle capillary network have been critical in promoting a greater understanding of how the vasculature meets the unique needs of each muscle fiber type (AI-Shammari et al. 2014; Egginton and Gaffney 2010; Plyley 1990; Plyley and Groom 1975).

\section{Adaptation of the capillary network with muscle activity}

capillary number within muscle is not static, but that it can vary dependent on changes in muscle activity. Angiogenesis is defined as the growth of new capillaries from pre-existing 
ones; it ensures that increases in skeletal muscle metabolic capacity are matched with an increased capacity for small molecule exchange. For example, oxygen diffusion is optimized by virtue of an increased surface area for exchange and reduced diffusion distance. Carrow and colleagues (Carrow et al. 1967) reported that a greater number of capillaries were present within the muscle of exercised rats compared to their sedentary counterparts. While the authors concluded that this phenomena was due to an increased number of perfused capillaries following exercise, in retrospect, this study likely represented one of the first observations of the phenomenon known as exercise-induced angiogenesis. Subsequently, the use of rabbit and rat models of electrical stimulation -induced muscle activity, together with standard histological and intra-vital microscopy techniques, provided unequivocal evidence that expansion of the capillary network occurs via addition of new capillaries in glycolytic muscle subjected to a sustained increase in metabolic demand (Brown et al. 1976; Cotter et al. 1973; Myrhage and Hudlická 1978). Concurrently, researchers made significant progress in demonstrating that these processes were not confined to animal models, but were valid also in human skeletal muscle. In the early 1970s, Hermansen and Wachtlova (1971) reported higher capillary to fiber ratio in trained compared to untrained individuals a finding later confirmed by Andersen (1975). However, Andersen and Henriksson's seminal study (1977), based on histological analysis of muscle biopsies from individuals before and through-out 8 weeks of training, provided the first direct evidence that exercise induced capillary growth occurs in human skeletal muscle. These researchers also demonstrated that maximal oxygen consumption increased with a similar time frame as the increases in capillary density, thus postulating a causal relationship between capillary number and improvements in maximal oxygen consumption.

\section{What stimulates exercise induced angiogenesis?}

Exercise is a multi-factorial stimulus, with numerous likely contributors to the initiation of the angiogenic response. These stimuli can be distinguished generally as being metabolic or mechanical in nature. Investigators have attempted to characterize the contributions of these stimuli, employing experimental models that allow independent manipulation of an individual 
97 stimulus. However, it should be emphasized that exercise evokes simultaneous changes in all of these factors.

Hypoxia and Metabolites: Reduced oxygen tension appears to be a strategic stimulus for the purpose of initiating a negative feedback loop that would culminate in capillary growth and enhanced oxygen delivery. However, the contribution of hypoxia to exercise induced angiogenesis remains controversial. Numerous studies have documented a transient reduction in intramuscular $\mathrm{pO}_{2}$ at the initiation of exercise, but $\mathrm{pO}_{2}$ is restored rapidly by the concomitant increase in muscle blood flow (Hudlicka 1998; Milkiewicz et al. 2003; Molé et al. 1999; Richardson et al. 1995). However, at high workloads, enhanced perfusion may be insufficient to restore oxygen deficit (Richardson et al. 1995). Thus, the magnitude and duration of a hypoxic challenge during exercise likely depends heavily on muscle workload and the potential for blood flow restriction due to elevated intramuscular pressures. Adenosine, which may be released during, and in proportion to, muscle activity also exerts angiogenic influences (Høier et al. 2010).

Mechanical Stresses: Muscle overload, induced experimentally when a muscle is required to bear the load of a synergistic muscle, increases metabolic demand, alters tensile strain and results in muscle hypertrophy and new capillary growth (Egginton et al. 1998; Holly et al. 1980; James 1981). While metabolic stress associated with muscle overload likely contributes to the induction of an angiogenic response in this model, several studies indicate that tensional forces associated with the stretch of muscle also contribute to the angiogenic process (Egginton 1998; Egginton 2011). Capillaries are tethered through extracellular matrix to the surrounding muscle tissue. Thus, capillary shape is altered and stretched with increases in sarcomere length (Ellis et al. 1990). Cultured endothelial cells subjected to static stretch increase production of proangiogenic factors (Milkiewicz et al. 2007b). In accordance with this concept, the interstitial

122 endothelial cell proliferation (Hellsten et al. 2008; Hoier et al. 2013b). Stretch/overload may 123 activate integrins on the abluminal surface of the endothelium and induce signaling to promote endothelial cell proliferation. Secretion of growth factors from fibroblasts, smooth muscle cells 
125 and pericytes, as well as release of matrix-associated growth factors, can contribute to this angiogenic response.

127 Shear stress refers to the frictional force generated on the endothelial cell surface as blood

128 flows. In resting muscle, capillary shear stress is estimated to be 5 dynes $\cdot \mathrm{cm}^{-2}$. During activity, 129 vasodilation of upstream arterioles increases muscle blood flow and results in capillary shear 130 stresses of $15-20$ dynes $\cdot \mathrm{cm}^{-2}$. Clarke (1918) first proposed the link between blood flow and 131 capillary growth by observing the growth of capillaries in tadpole tails. By observing the same 132 region over the course of weeks, he observed that areas with high velocity formed new vessels 133 while in low velocity areas, vessel number diminished. The administration of vasodilator drugs 134 has been used to isolate the impact of increased blood flow from muscle metabolism in order 135 to investigate its effects on capillarization. Treatment with the alpha-1 adrenergic receptor 136 antagonist, prazosin, causes a sustained increase in capillary shear stress that is similar to the 137 level achieved during muscle activity (Davey 1982; Ziada et al. 1989), and an increase in 138 capillary to fiber ratio is detectable within 7-14 days (Gee et al. 2010; Rivilis et al. 2002; Zhou et 139 al. 1998).

\section{Sprouting and non-sprouting angiogenesis}

142 The formation of new capillaries has been documented to occur via two distinct morphological 143 processes; abluminal sprouting and luminal splitting/intussusception. The former involves a 144 coordinated sequence of events including proliferation of endothelial cells, spatially restricted 145 proteolytic degradation of the capillary basement membrane, and migration of sprouting tip 146 cells into the interstitial (Fischer et al. 2006; Geudens and Gerhardt 2011). The sprout forms an anastomosis with another capillary and a patent lumen is formed, generating a new flow channel (Geudens and Gerhardt 2011). This type of angiogenesis has been observed with 149 muscle activity, such as that evoked by chronic electrical stimulation (Myrhage and Hudlická 150 1978).

151 Intussusception has been described in models of blood flow-induced angiogenesis (Clark and 152 Clark 1940; Patan et al. 1993). In skeletal muscle, this process has been identified as "luminal 
153 splitting". It occurs when capillary endothelial cells forming luminal protrusions that bridge 154 across the lumen and fuse with the opposite wall, which generates 2 parallel flow channels

155 (Zhou et al. 1998). These flow channels then separate into two distinct capillaries, which may 156 occur due to forces exerted by perivascular cells. Unlike sprouting angiogenesis, splitting

157 involves minimal proliferation and is not associated with proteolytic degradation of the 158 basement membrane. Intussusception describes a similar process in which luminal pillars that are comprised both of endothelial cells and surrounding perivascular cells form bridges across the vessel and generate multiple flow pathways (Styp-Rekowska et al. 2011). In each case, remodeling is stimulated by elevated shear stress and it helps the microvascular network to adapt rapidly to local changes in shear stress while maintaining the overall branching hierarchy of the microvascular network.

Sprouting and splitting types of capillary growth result in morphologically distinct capillary networks. While sprouting angiogenesis creates a network that is dominated by many short inter-connecting capillary loops, splitting angiogenesis generates a network comprised of numerous long capillaries in parallel. Aerobic muscle activity does elicit both forms of angiogenesis (Egginton et al. 2001). From a therapeutic point of view, it is attractive to consider that there may be an opportunity to stimulate angiogenesis through manipulation of blood flow and induction of luminal splitting even if sprouting angiogenesis is limited.

Angiogenic Balance: Factors that modulate angiogenesis

172

173

174

175

176

177

178

179

180

Judah Folkman, who pioneered research in the field of tumour angiogenesis, provided evidence that capillary growth is controlled by a specific factor that initially was identified simply as "tumour angiogenesis factor" (Gimbrone et al. 1972; Sherwood et al. 1971). Folkman postulated that inhibition of this factor could be used to control tumour angiogenesis, and hence, tumour growth. Subsequently, his research extended to the identification of multiple endogenous inhibitors of angiogenesis (Folkman 1996). This research provided the framework for understanding the process of angiogenesis in a variety of pathological and physiological conditions. It is now appreciated that angiogenesis within skeletal muscle is tightly controlled by a balance between pro- and anti- angiogenic signals (Gustafsson 2011; Olfert \& Birot 2011). 
181 An abundance of pro-angiogenic factors favours the growth of new capillaries while an excess

182 of anti-angiogenic factors restricts new capillary growth and may result in the loss, or

183 rarefaction, of pre-existing capillaries. In the adult, it is appropriate to maintain stable mature

184 capillary networks within most tissues, and this requires a net balance between growth and

185 regression stimuli. Over the past 30 years, dozens of factors that exert pro- or anti-angiogenic

186 functions have been identified and characterized in a wide variety of model systems. This

187 review will be limited to the description of the best characterized factors that been investigated

188 within skeletal muscle.

189

190

Pro-Angiogenic Factors:

191

192

193

194

195

196

197

198

199

200

201

202

203

204

205

206

207

208

209

Vascular Endothelial Growth Factor-A (VEGF-A) is the most widely studied pro-angiogenic molecule and is capable of stimulating all aspects of the angiogenic sprouting process. Multiple isoforms of VEGF-A (typically identified by their amino acid length) are generated as a consequence of alternative splicing of the primary mRNA transcript (Neufeld et al. 1996). These isoforms differ predominantly in their capacity to bind heparin sulphate proteoglycans within the extracellular matrix. VEGF-A $\mathrm{A}_{165}$ and VEGF-A 189 , both which contain the heparin sulfate binding domain encoded in exon 6 , together constitute approximately $70 \%$ of the VEGF-A transcript produced by human skeletal muscle, irrespective of fibre type (Gustafsson et al. 2005). Much of this secreted VEGF-A is retained within the matrix surrounding the capillaries. The deposition of matrix-associated VEGF-A may establish a chemotactic gradient that attracts and guides the tip cells of capillary sprouts (Vempati et al. 2014). We found that VEGF-A secreted by $\mathrm{C} 2 \mathrm{C} 12$ myoblasts is retained in the cell-free extracellular matrix and that it can in turn activate angiogenic signaling in cultured endothelial cells (Gorman et al. 2014). On the other hand, endothelial cells produce a higher amount of VEGF-A $A_{121}$ (Gorman et al. 2014), which lacks exon 6 and thus is freely diffusible within the extracellular fluid. While all isoforms of VEGF-A bind to and activate VEGFR2, only isoforms with exon 7 (in muscle, VEGF-A-165,189) interact with the co-receptor neuropilin-1. It is postulated that this interaction may result in differences in the dynamics of receptor localization and internalization as well as promote unique intracellular signal pathways (Plein et al. 2014). Numerous cells within the skeletal 
210 muscle produce and secrete VEGF-A, including myofibres, endothelial cells, satellite cells, 211 fibroblasts and macrophages (Maharaj et al. 2006). Despite these multiple cellular sources of

212 VEGF-A, studies utilizing mice that are deficient in skeletal myofibre VEGF-A have provided clear 213 evidence that myofibre-derived VEGF-A is critical in promoting angiogenesis in response to a 214 metabolic stimulus such as exercise or muscle overload (Gorman et al. 2014; Olfert et al. 2010).

216 In muscle, production of VEGF-A is enhanced by hypoxic and metabolic stress (De Bock et al. 217 2013; Hoier and Hellsten 2014). This pattern of regulation strongly suggests that VEGF-A 218 production is linked in tight association with the metabolic needs of the myofibres. Distinct 219 from this established paradigm, we demonstrated recently that nitric oxide (a signaling 220 mediator generated by endothelial cells in response to elevated shear stress) can promote 221 skeletal myocyte production of VEGF-A (Uchida et al. 2015). Furthermore, deficiency in 222 myocyte-derived VEGF-A resulted in a loss of blood flow-induced angiogenesis (Uchida et al. 223 2015). These findings also serve to highlight the significance of bi-directional cross-talk between 224 capillary endothelial cells and the surrounding skeletal myofibres in co-ordinating appropriate 225 adaptive responses within the microvascular network.

Matrix Metalloproteinases (MMPs) are responsible for proteolysis of the matrix proteins that comprise the capillary basement membrane, allowing for tip cell sprouting during abluminal sprouting angiogenesis (Brew and Nagase 2010; Haas and Madri 1999). MMP activity is essential for activity-induced angiogenesis as the pharmacological inhibition of MMP enzymatic activity prevented basement membrane proteolysis, abluminal sprout formation and new capillary growth in rat EDL muscle in response to prolonged electrical stimulation of muscle activity (Haas et al. 2000). The MMP family is extensive, however, several family members (MMP-2, MMP-9 and membrane type 1 (MT1)-MMP/MMP-14) have been reported to increase in exercising muscle in rats and humans, prior to the detection of increased capillary number (Haas et al. 2000; Rullman et al. 2007, 2009). MMP-9 cleaves heparan sulfate proteoglycans, 238 facilitate rapid activation of pro-angiogenic signaling within the local environment in response 
239 to exercise. In contrast, the process of flow-induced capillary growth does not involve basement membrane degradation and there is no increase in production of MMPs (Rivilis et al. 2002). In fact, cultured endothelial cells exposed to elevated blood flow exhibit reduced levels of MMP-2 and MT1-MMP and increased production of the protease inhibitor TIMP1 (Milkiewicz et al. 2006b, 2008; Yun et al. 2002), which together may ensure stability of the capillary basement membrane.

Angiopoeitins (ANGPT1 and ANGPT2) are ligands for the tyrosine kinase receptor Tie2. ANGPT1-induced activation of Tie2 is associated with enhancement of pericyte-endothelial cell interactions, strengthening of endothelial-endothelial junctions and the maintenance of a stable capillary network (Augustin et al. 2009). ANGPT1 and ANGPT2 may be produced by satellite cells and skeletal myocytes as well as by endothelial cells. ANGPT2 expression can be stimulated by hypoxia and by VEGF-A (Andersson et al. 1988; Oh et al. 1999; Yuan et al. 2000). ANGPT2 competes for binding to Tie2, but is considered to be a weak receptor agonist that functions as a competitive antagonist of ANGPT1, preventing activation of the receptor and downstream signal pathways (Thurston and Daly 2012). Consequently, elevated levels of ANGPT2 reduce Tie2 activation, and vessel de-stabilization may result. If this occurs with concurrent activation of the VEGF-A/VEGFR2 pathway, ANGPT2 enhances the sprouting angiogenic process. However, in the absence of VEGF-A signaling, elevated levels of ANGPT2 can promote endothelial cell death and vessel regression (Fagiani and Christofori 2013).

Nitric Oxide (NO) is produced in endothelial cells through the enzymatic activity of endothelial nitric oxide synthase (eNOS, or NOS3) (Förstermann and Sessa 2012). eNOS catalyzes the conversion of L-arginine and molecular oxygen to NO and L-citrulline. eNOS exhibits basal constitutive activity, which can be enhanced by elevated intracellular calcium and by 262 phosphorylation of Ser1177 by Akt (Sessa 2009). These intracellular signals are stimulated by endothelial cell exposure to elevated shear stress as well as by numerous growth factor 264 receptors that recruit Akt as part of their intracellular signaling network. Within arterioles, NO 265 diffuses to the surrounding vascular smooth muscle cells, stimulating guanylate cyclase-cGMP266 protein kinase G-dependent relaxation. In addition to the critical role that NO plays in the 
267 modulation of vascular smooth muscle tone, NO has been shown to exert pro-angiogenic 268 influences (Morbidelli et al. 2003; Papapetropoulos et al. 1997). Indirectly, NO production and 269 arteriolar vasodilation induces angiogenesis as a consequence of increasing blood flow through the downstream capillaries. However, cultured cell experiments demonstrate that elevated

$271 \mathrm{NO}$, in the absence of a flow stimulus, increases endothelial cell proliferation and migration

272 (Morbidelli et al. 1996). Our recent observation that NO stimulates skeletal myocyte

273 production of VEGF-A provides further explanation of a mechanism through which endothelial 274 cells can relay messages to the surrounding tissue to co-ordinate and enhance pro-angiogenic 275 signals (Uchida et al. 2015). Considering these pleiotropic influences of NO, it is not surprising 276 that the capacity of skeletal muscle capillaries to undergo angiogenesis in response to 277 metabolic or to blood flow stimuli is significantly impaired by pharmacological inhibition of 278 eNOS activity or by genetic knock-out of NOS3 (Baum et al. 2004; Hudlická et al. 2000; Williams 279 et al. 2006).

280 Angiotensin II (Ang II) has been shown to play a role in angiogenesis during skeletal muscle 281 regeneration (Bellamy et al. 2010). Ang II treatment of endothelial cells in vitro enhanced tube 282 formation and migration (Bellamy et al. 2010). Stimulation with exogenous Ang II was reported 283 to upregulate ANGPT2 mRNA in cultured retinal endothelial cells (Otani et al. 2001) and to 284 increase VEGF-A and MMP-2 mRNA levels in both C2C12 myocytes and microvascular endothelial cells (Gorman et al. 2014). While in vitro experiments indicate a pro-angiogenic role of Ang II, evidence that it is a significant contributor in the context of physiological skeletal muscle angiogenesis is mixed. Amaral and colleagues reported that the AT1 receptor inhibitor losartan prevented activity-induced angiogenesis (Amaral et al. 2001a, 2001b). However, losartan did not interfere with VEGF-A production or angiogenesis in response to muscle overload (Gorman et al. 2014). Other studies have reported a pro-angiogenic influence of 291 losartan in tumour growth and within the brain microvasculature (Forder et al. 2005;

292 Munzenmaier and Greene 2006; Walther et al. 2003). A challenge in the interpretation of these 293 findings is that Ang II can activate multiple receptors sub-types and the relative distribution of 294 these receptor sub-types differs between vascular beds. Further, use of losartan was reported 295 to induce compensatory increases in circulating levels of Ang II (Munzenmaier and Greene 
2006), which in turn could promote conversion to Ang(1-7) through the actions of angiotensin converting enzyme 2. Consequently, utilization of an AT1 receptor blocker such as losartan may provoke the over-activation of AT2 or Ang(1-7) (mas) receptors, which by themselves have been reported to induce both pro- and anti-angiogenic effects. Considering the known complexity of this signaling axis and the divergent angiogenic influences that have been reported to date, it is apparent that a complete understanding of how Ang II may contribute to the process of skeletal muscle angiogenesis remains to be established.

\section{Anti-angiogenic Factors:}

Tissue Inhibitor of Matrix Metalloproteinases (TIMPs) are proteins that restrict the activity of MMPs (Brew and Nagase 2010). They interact with the catalytic domain of the MMPs, preventing MMP access to ligands. They also can interfere with the activation process, which requires cleavage of a pro-domain from the MMP. By restricting MMP activity, TIMPs tend to reduce the remodeling of extracellular matrix proteins and cleavage of cell surface proteins. However, these actions ultimately may inhibit or promote angiogenic signaling. For example, cleavage of extracellular matrix proteins may expose pro-angiogenic domains, but it also can cause the release of anti-angiogenic fragments such as angiostatin (described below) (Suhr et al. 2009). In this case, inhibition of proteolytic activity prevents such anti-angiogenic actions. It also has been proposed that TIMPs exert cellular functions independently of MMP inhibition (Ries 2014). For example, TIMP1 is postulated to exert pro-proliferative and pro-survival cues in cancer cells (Stetler-Stevenson 2008). However, we have not been able to detect this effect in cultured endothelial cells (Mandel et al. 2014), thus the potential relevance of these functions to endothelial cell behaviour remains poorly established. We found that exposure of endothelial cells to elevated shear stress induces the increased production of TIMP1, indicating that TIMP1 may play a protective anti-proteolytic role that assists in maintaining capillary integrity in the face of elevated hemodynamic stress (Milkiewicz et al. 2008; Uchida and Haas 2014).

Endostatin and Angiostatin: Proteolytic cleavage of the C-terminal domain of collagen XVIII releases a $20 \mathrm{kDa}$ fragment that is referred to as endostatin (O'Reilly et al. 1997). MMP-9 is 
324 among the group of MMPs and elastases capable of generating this cleavage product (Ferreras

325

326

327

328

329

330

331

332

333

et al. 2000). Endostatin exerts anti-angiogenic functions by competing with collagen for binding to integrins $\alpha v$ and $\alpha 5$, and thus interfering with migration and cell survival signaling (Faye et al. 2009). Angiostatin is a $38 \mathrm{kDa}$ cleavage fragment of plasminogen, and has been shown to inhibit endothelial cell proliferation and induce apoptosis (O’Reilly et al. 1994). Through interactions with the cell surface receptor angiomotin, it may interfere with cell-matrix attachment and cell migration (Troyanovsky et al. 2001). Because of the increased activity of MMPs in response to exercise, it is feasible to expect increased production of these angiostatic cleavage products. However, their contributions to the process of capillary growth in muscle have been difficult to ascertain, in part because it requires accurate detection of the cleavage peptide rather than detection of mRNA or the originating protein. It is notable that elevated levels of endostatin and angiostatin have been found within skeletal and cardiac muscle of diabetic patients and rodents with metabolic syndrome (Dodd et al. 2013; Sodha 2008), suggesting that these factors may contribute to establishing the general balance between pro and anti-angiogenic factors within muscle under basal conditions and have greater relevance under disease conditions.

Thrombospondin-1 (THBS1) is a large matricellular protein that interacts with dozens of secreted and matrix proteins and multiple cell surface receptors (Adams 1997; Resovi et al. 2014; Silverstein et al. 1986). THBS1 also regulates the activation of latent transforming growth factor $\beta$ (TGF $\beta$ ), implicating it indirectly in promoting the fibrotic influences associated with TGF $\beta$ signaling (Murphy-Ullrich and Poczatek 2000). Considering the diversity of these interactions, it is not surprising that THBS1 has been reported to exert numerous cell and context-specific biological functions (Chen et al. 2000). THBS1 can inhibit endothelial cell proliferation and migration and induce endothelial cell apoptosis, and thus is considered to be a potent anti-angiogenic factor (Iruela-Arispe et al. 2004). Consistent with this influence, the deletion of THBS1 increases basal capillary number in skeletal and cardiac muscle and enhances exercise capacity in mice (Malek and Olfert 2009).

\section{Intracellular Regulators of Angiogenic Status}


353 Considering that multiple factors exert positive and negative influences on the angiogenic

354 process within the muscle, capillary growth requires some degree of co-ordinated regulation of

355 these factors. It is attractive to consider the involvement of "master regulators", which could

356 integrate the signals originating from the various exercise-dependent stimuli in order to elicit a

357 program of alterations that enhance angiogenic responsiveness. Transcription factors have the

358 potential to act in this role given their capacity to promote transcription of a set of genes.

359 Hypoxia Inducible Factors: Low cellular oxygen levels stabilize the transcriptional regulators

360 hypoxia inducible factors (HIF) $1 \alpha$ and $2 \alpha$. This occurs due to reduced targeting of HIF $\alpha$ for

361 degradation as a consequence of inhibition of the oxygen-sensitive prolyl hydroxylase. Either

362 HIF1 $\alpha$ or HIF2 $\alpha$ forms a functional DNA binding protein with HIF1 $\beta$ and acts to enhance the

363 transcription of numerous genes that contain hypoxia-response elements (HRE) (Semenza

364 2014). HIF1 $\alpha$ is an established transcriptional regulator of VEGF-A (Pugh and Ratcliffe 2003)

365 and it also increases production of ANGPT2 (Mandriota and Pepper 1998), suggesting that it co-

366 ordinates the expression of these two growth factors to promote an angiogenic response.

367 HIF1 $\alpha$ plays an important role in exercise induced angiogenesis. Destabilization of HIF proteins

368 prevented overload-induced angiogenesis in rats (Milkiewicz et al. 2007a). Furthermore,

369 exercise-induced angiogenesis failed to occur in mice lacking skeletal muscle HIF1 $\alpha$ (Mason et

370 al. 2007). The latter study has been suggested as evidence that hypoxia is an important

371 stimulus of exercise-driven capillary growth. However, HIF1 $\alpha$ transcriptional activity can be

372 induced independently of hypoxia, via stimuli such as mechanical stretch and growth factors,

373 which appear to act through MAPK signaling and generation of reactive oxygen species (Chang

374 et al. 2003; Milkiewicz et al. 2007a; Richard et al. 2000). Interestingly, endurance athletes have

375 elevated levels of enzymes that negatively regulate HIF1 $\alpha$ (prolyl hydroxylases and factor

376 inhibiting HIF), and lower levels of HIF target genes, indicating a reduced reliance on HIF-

377 dependent signal pathways with sustained endurance training (Lindholm et al. 2014a).

378 Peroxisome-proliferator-activated receptor $\gamma$ co-activator $1 \alpha(\mathrm{PGC1} \alpha)$ is a transcriptional co-

379 activator that is active in situations of intracellular energy deficit. In humans, PGC1a mRNA

380 increases in active muscle following a single exercise bout, and this is augmented under flow- 
381 restricted conditions (Norrbom et al. 2004), consistent with its role as an "energy/metabolism 382 sensor". PGC1 $\alpha$, through interaction with estrogen-related receptor (ERR) $\alpha$, enhances VEGF-A 383 transcription in response to hypoxic or metabolic stress (Arany et al. 2008). PGC1- $\alpha$ /ERR- $\alpha$ also 384 was shown to contribute significantly to the upregulation of VEGF-A, and the induction of 385 capillary growth in response to exercise in mice (Chinsomboon et al. 2009).

Forkhead family Box 01 (FoxO1) is a transcription factor that has been established to exert antiangiogenic effects through regulating the transcription of downstream targets such as cyclinD1 and $\mathrm{p} 27^{\mathrm{Kip} 1}$ (Eijkelenboom and Burgering 2013) as well as eNOS, Sprouty2 (an inhibitor of the MAPK pathway) and THBS1 (Paik et al. 2007; Potente et al. 2005; Roudier et al. 2013b). Overexpression of FoxO1 also leads to a reduction in VEGF-A mRNA (Shikatani et al. 2012). We found that mice deficient in endothelial FoxO proteins exhibited an accelerated capillary growth in response to exercise training (Slopack et al. 2014). Since FoxO proteins can regulate the transcription of multiple genes, including cell cycle regulators and mediators of cell migration, it is probable that FoxO proteins exert their restraining influence through a number of gene 395 targets.

Murine double minute ( $\mathrm{Mdm} 2$ ) (or its human counterpart $\mathrm{Hdm} 2$ ) is an E3 ubiquitin ligase with a well-established role as a regulator of the tumour suppressor p53, which it poly-ubiquitinates, thus targeting it for proteasomal degradation. Mdm2 also promotes HIF1 $\alpha$ stabilization, which can in turn facilitate a higher level of VEGF-A transcription (Carroll and Ashcroft 2008). Recent data indicate that Mdm2 is an important regulator of VEGF-A production in skeletal muscle. Mdm2 levels are elevated in muscle of exercise trained mice and humans (Roudier et al. 2012, 2013a). Mice with reduced levels of Mdm2 exhibited lower basal muscle capillarization and a diminished capacity to increase VEGF-A, or to increase capillary number, with exercise (Roudier et al. 2012). These findings illustrate the significant role of Mdm2 in regulating muscle production of VEGF-A. Mdm2 also interacts with FoxO1 in endothelial cells: Mdm2 protein level and phosphorylation status correlates inversely with FoxO1 protein expression, suggesting 407 that Mdm2 is in fact a negative regulator of FoxO1 (Milkiewicz et al. 2011; Roudier et al. 2012). 
410 To gain a comprehensive understanding of the regulation of exercise-induced angiogenesis, it is 411 crucial to integrate data for the timing and magnitude of changes in the various angiogenic 412 factors and consider the cumulative effects of the modulation of all of these individual factors.

413 Below and in Fig. 2, the data available for alterations in angiogenic and anti-angiogenic factors 414 over the course of exercise training are summarized in 3 distinct stages: 1) a single bout of 415 aerobic exercise; 2) repeated bouts of aerobic exercise; or, 3) sustained (long term) aerobic 416 exercise training. Consideration is given to the cellular/extracellular niche associated with 417 these factors, based on current knowledge.

Stage 1: A single bout of aerobic exercise (Fig. 2A) disrupts homeostasis within the active muscle, simultaneously initiating multiple "stress" signals that are generated by the combined reduction of tissue $\mathrm{pO} 2$, generation of metabolites, elevated capillary shear stress, NO production and tensional stress on myocytes and capillaries. A single bout of exercise induces a significant transient increase in VEGF-A mRNA and protein in muscle (Birot et al. 2003; Breen et al. 1996; Gustafsson et al. 1999; Richardson et al. 1999). VEGF-A production may be driven by altered activity of HIF1 $\alpha$, as its protein level and DNA binding activity increases with an acute exercise bout (Ameln 2005) or by PGC1 $\alpha$, which also increases in active human muscle, particularly under flow-restricted conditions (Norrbom et al. 2004). Mdm2 contributes to the acute increase in myocyte VEGF-A (Roudier et al. 2012). An acute bout of exercise also stimulates the exocytosis of VEGF-A from vesicles within the myocytes and the potential release of matrix-associated VEGF-A protein by MMP-9 (Hoier et al. 2013a; Rullman et al. 2007). Together, these alterations are expected to enhance VEGF-A bioavailability, increasing VEGF-A binding to VEGFR2 and the activation of downstream signaling. When exercise ceases, the stimuli return to basal (pre-exercise) levels and, within several hours post-exercise, so do the mRNA and protein levels of VEGF-A. ANGPT2 and Tie2 mRNA also increase in response to an acute exercise bout (Hoier et al. 2012; Lloyd et al. 2003). However, there is no evidence for an increase in ANGPT2 protein with an acute exercise bout (Gustafsson et al. 2007), thus it is unlikely that ANGPT2 plays a major role in the acute exercise response. Increased endothelial 
437 cell proliferation, sprouting or luminal splitting is not detectable after a single exercise bout 438 (Egginton 2009). It is possible that a threshold, in terms of duration and/or magnitude of 439 signal, must be attained in order to accumulate sufficient intracellular changes in protein expression/activation to drive these complex cellular processes.

However, the simultaneous activation of anti-angiogenic signals, which exert opposing

442 intracellular signals, also will repress angiogenic behaviour. In mice, an acute exercise bout has 443 been reported to increase levels of VEGFR1 (Birot et al. 2003), which acts as a competitive 444 antagonist of VEGFR2 signaling. Endostatin levels within muscle homogenates were reported 445 to increase following a single exercise bout (Olenich et al. 2013). THBS1 mRNA and protein 446 levels increase transiently with a single bout of exercise (Hoier et al. 2012; Slopack et al. 2014), 447 driven by increases in FoxO proteins (Slopack et al. 2014).

Stage 2: Adaptations to the acute exercise response (Fig. 2B) begin to be detectable as training 449 continues (i.e. 7 days to 2 weeks). The "basal" level of VEGF-A protein shows a tendency to increase in some studies (Gustafsson et al. 2007; Olenich et al. 2013). This could reflect an accumulation of VEGF-A, for example, if the half-life of VEGF-A protein is long enough that protein levels do not return to basal before the subsequent exercise bout again stimulates new production of VEGF-A. This in turn should extend the duration of VEGFR2 activation on the adjacent capillary endothelial cells, potentially sufficient to trigger the necessary intracellular signals for cell cycle progression and tip cell formation. Interestingly, repeated training appears to reduce HIF1 $\alpha$ mRNA (Lundby et al. 2006), suggesting that it may not play a dominant role in maintaining the continued expression of VEGF-A with repeated training. Increased production of VEGFR2 with exercise training also promotes enhanced VEGF-A dependent signaling (Gustafsson et al. 2007; Lloyd et al. 2003). At the same time, exercise training results in 460 elevated basal levels of ANGPT2 mRNA and protein (Gustafsson et al. 2007), which may 461 facilitate the processes of endothelial cell sprouting. Increased production of MMP-2 and 462 MMP-14, potentially driven by VEGFR2 signaling, is evident after 7-10 days of muscle activity 463 (Haas et al. 2000; Ispanovic and Haas 2006; Rullman et al. 2009). These enzymes will facilitate 464 basement membrane proteolysis and sprout extension into the extracellular matrix. 
465

466

467

468

469

470

471

472

473

474

475

476

477

478

479

480

481

482

483

484

485

486

487

488

489

490

491

492

Interestingly, increased levels of TIMP1 mRNA were detected in muscle after 10 days to 5 weeks of exercise training (Rullman et al. 2007, 2009). Similarly, TIMP1 protein was found to increase post-exercise in exercise trained individuals (Hoier et al. 2012). The role played by TIMP1 in this context is not well established. eNOS mRNA levels also are increased by exercise training in ischemic rat muscles, suggesting that NO production capacity might be increased with training (Lloyd et al. 2003).

While these pro-angiogenic signals accrue, the increase in THBS1 mRNA in response to acute exercise is restrained with training (Slopack et al. 2014). In mice, this correlates closely with a reduction in both FoxO1 and FoxO3a mRNA and protein, which exhibit a lack of increase in response to exercise after 7 days of training (Slopack et al. 2014). Mdm2 may contribute to the restraint of FoxO proteins through inducing their ubiquitination and degradation (Milkiewicz et al. 2011). Thus, the reduced inhibitory influence of FoxO/THBS1 should have the consequence of enhancing endothelial cell responsiveness to VEGF-A and other pro-angiogenic factors. However, the acute exercise response of THBS1 mRNA remained detectable in humans with exercise training (Hoier et al. 2012), thus there may be aspects related to exercise intensity and/or frequency that modulate the effectiveness of FoxO/THBS1 down-regulation.

Stage 3: Attainment of a trained steady-state (Fig. 2C) occurs after 4-8 weeks, when training is repeated without continuous increases in workload. After 4-8 weeks of continual training, many pro-angiogenic (MMPs, HIF $\alpha$, VEGF-A) and anti-angiogenic (THBS1) factors are no longer different from pre-training levels (Hoier et al. 2012; Lundby et al. 2006; Olenich et al. 2013; Richardson et al. 2000). Basal levels of THBS1 protein were reported to increase after 28 days of training in mice (Olenich et al. 2013); however, no change in basal THBS1 mRNA or protein was detectable in human skeletal muscle after training (Hoier et al. 2012). Alterations in the levels of some factors may facilitate the establishment of a mature and stable capillary network. For example, Tie2 was found to increase following repeated exercise bouts in rats (Lloyd et al. 2003), which may help to stabilize endothelial cell junctions. Microarray analysis of muscle from endurance trained individuals provided evidence for increased mRNA levels of vessel stabilization factors that are known to promote basement membrane deposition and 
493 pericyte coverage (ANGPT1, Tie1, Tie2, TGF $\beta 2$ and TGF $\beta$ R2) (Timmons et al. 2005).

494 Conceptually, this reduced responsiveness is thought to occur because the adaptations in 495 capillary number (together with concomitant adaptations within the skeletal myocytes) that 496 took place during the initial stages of training have contributed in a negative feedback loop to 497 reduce the magnitude of the stimuli that initiated angiogenesis. Alternatively, epigenetic 498 modifications such as DNA methylation have been reported to occur in muscle as a 499 consequence of long term training (Lindholm et al. 2014b), which also could contribute to the 500 shift in expression pattern of angiogenic factors by modulating transcription factor access to 501 the promoter enhancer regions of these genes. Ultimately, the degree to which an individual's 502 capillary network adapts to training is affected by their genetic predisposition to mount an 503 effective adaptive response (Keller et al. 2011). However, the characteristics that define a 504 "responder" require further elucidation.

505 In summary, the stimulus of exercise initially evokes the production or activation of both pro506 and anti-angiogenic factors. At this initial time point, the pro-angiogenic factors are not

507 sufficiently strong or long in duration to enable the initiation of capillary sprouting. However, 508 angiogenic growth factors accumulate with repeated exercise bouts, provoking sustained 509 alterations in intracellular signaling that serve to stimulate endothelial cell proliferation and 510 sprouting as well as to repress the production of anti-angiogenic factors. The precise timing for transition to this state is likely highly dependent on a combination of factors including parameters of the exercise regimen as well as the individual's baseline levels of pro- and antiangiogenic regulators, as influenced by genetic/epigenetic mechanisms. A new steady state is

515 longer provoke the magnitude of intracellular signals required to maintain the angiogenic 516 cascade.

\section{Pathophysiological Influences affecting Skeletal Muscle Capillary Networks}

518 The balance achieved between capillary density and muscle metabolic demand in healthy 519 individuals can be disrupted in various disease states, which can have profound negative effects 520 on muscle performance and whole body metabolic homeostasis. It is relevant to consider both 
521 the underlying influences of these diseases on capillaries within the muscle microenvironment

522 as well as the potential of exercise therapy to enhance capillary number and improve muscle

523 function.

$524 \quad$ Peripheral Artery Disease (PAD)

525 PAD is characterized by reduced blood flow (commonly to the lower limb), which causes muscle 526 ischemia, claudication (intermittent leg pain) and reduced exercise tolerance. Ultimately, this condition may deteriorate to the point of critical limb ischemia, which is such an extreme reduction in limb blood flow that it results in tissue necrosis necessitating amputation. Several studies have defined a strong positive correlation between capillary number and indicators of exercise tolerance such as peak oxygen consumption, peak walking time and time until onset of claudication (Askew et al. 2005; Duscha et al. 2011; Robbins et al. 2011). These data indicate that the extent of muscle capillarization is a major factor in determining exercise tolerance, and imply that an increase in capillarization can play a critical role in improving muscle function and, ultimately, the health of PAD patients (see Haas et al. 2012 for a more detailed review).

Although a marked reduction of oxygen tension occurs in the ischemic tissue, which is a key stimulus for induction of hypoxia-responsive genes including VEGF-A, capillary density remains unchanged or even is reduced within the ischemic lower leg muscles of PAD patients (Duscha et al. 2011; Henriksson et al. 1980; Jansson et al. 1988; Robbins et al. 2011). Increased expression of VEGF-A is observed within ischemic muscle, indicating that a lack of VEGF-A is not the underlying problem (Duscha et al. 2011; Couffinhal et al. 1998; Milkiewicz et al. 2006a). The paradoxical lack of angiogenesis in the presence of increased VEGF-A suggests that elevated

542 levels of intrinsic anti-angiogenic signals counter-act the actions of pro-angiogenic molecules.

543 Some studies have observed a reduction in VEGFR2 as well as increased levels of VEGFR1, which 544 may act as a competitive antagonist to VEGF-A/VEGFR2 signaling (Hazarika et al. 2007;

545 Imoukhuede et al. 2013; Milkiewicz et al. 2003). We found that FoxO1 is upregulated within 546 ischemic muscle of PAD patients, correlating with indicators of disease severity. In mice, 547 endothelial FoxO deficiency promoted new capillary growth in ischemic muscle (Roudier et al. 548 2013b). We and others have detected elevated levels of THBS1 in ischemic muscle, which is not 
549 surprising considering the capacity of FoxO1 to enhance THBS1 expression, (Chu et al. 2015;

550 Favier et al. 2005; Roudier et al. 2013b). Thus, work to date strongly supports the concept that

551 high levels of anti-angiogenic factors within the ischemic muscle impede the capacity for

552 capillaries to respond well to an angiogenic stimulus.

553 Obesity, Insulin Resistance and Type 2 Diabetes

554 Animal models have demonstrated that type 2 diabetes results in pronounced microvascular

555 dysfunction at the level of skeletal muscle arterioles, involving increased alpha-adrenergic tone, 556 greater ROS production and NO scavenging, and reduced insulin-dependent production of NO

557 (Barrett et al. 2011; Goodwill et al. 2008; Goodwill and Frisbee 2012; Novielli and Jackson 2014;

558 Xiang et al. 2008), resulting in a pro-inflammatory endothelial phenotype and excessive 559 vasoconstriction. Consequently, the volume of blood delivered to the downstream capillary 560 networks is reduced and also its distribution is more heterogeneous (i.e. a reduced proportion 561 of capillaries receive flow) (Benedict et al. 2011; Butcher et al. 2014; Ellis et al. 2010; Frisbee 562 2007; Padilla et al. 2006). These alterations impair oxygen delivery even under resting 563 conditions (Ellis et al. 2010), suggesting that these individuals will present with more severe ischemia when coupled with PAD. This is a significant health concern, because diabetic individuals are 2-3 times more likely to develop PAD than non-diabetic individuals (Norgren et al. 2007). Not surprisingly, revascularization interventions also are less successful in diabetic PAD patients, resulting in a greater than 20-fold higher life time risk for major amputation (Jude et al. 2010; Norgren et al. 2007).

While the important link between capillary density, metabolic exchange and insulin sensitivity is recognized, relatively few studies have investigated the impact of obesity on key regulatory mechanisms that control skeletal muscle capillarization. Several studies have reported a lower

572 capillary density in obese compared to healthy subjects (Gavin et al. 2005; Mårin et al. 1994).

573 Notably, rarefaction of microvessels in the skeletal muscle may be more severe when obesity is 574 associated with insulin resistance or diabetes (Pasarica et al. 2009; Solomon et al. 2011).

575 Diabetes may generate a microenvironment that represses the appropriate angiogenic 576 response to ischemia. Reactive oxygen species, which are elevated within skeletal muscle of 
577 insulin resistant and diabetic animals (Bonnard et al. 2008; Fridlyand and Philipson 2006),

578 appear to exert an anti-angiogenic influence (Ebrahimian et al. 2006). Endothelial cell apoptosis

579 was reported to be elevated within muscle of leptin receptor deficient mice $(d b / d b)$ compared

580 to WT controls and these mice also express higher levels of thrombospondin-1 (Emanueli et al.

581 2007). However, more research is needed to generate a comprehensive knowledge of the

582 cellular mechanisms that regulate muscle capillarization under diabetic conditions and to

583 understand how these signal pathways will influence the angiogenic responsiveness of skeletal

584 muscle capillaries within ischemic muscle.

585 Exercise has been shown to stimulate the upregulation of angiogenic factors such as VEGF-A 586 and VEGFR2 in ischemic and diabetic muscle (Kivelä et al. 2008; Lloyd et al. 2003). However, the 587 magnitude of these responses may be smaller than that detected in healthy muscle. From the 588 perspective that angiogenesis is governed by the balance between pro-angiogenic and anti589 angiogenic signals, it is likely that increased levels of anti-angiogenic factors within ischemic 590 and/or diabetic microenvironment will impede or delay the initiation of angiogenesis in 591 response to exercise.

\section{Concluding Perspective}

593 Angiogenesis is a long term adaptive process that is important in optimizing the delivery of 594 oxygen and nutrients to meet chronic alterations in the local metabolic needs of skeletal 595 muscle. It is recognized that insufficiencies in angiogenesis contribute to limited improvements 596 in exercise adaptations in some individuals and underpin the skeletal muscle dysfunction in 597 conditions such as peripheral artery disease and diabetes. While significant progress has been 598 made in defining factors that promote capillary growth, it is evident that multiple gaps in 599 knowledge remain related to the integration of angiogenic responses. Research methodologies 600 often exacerbate the challenges in understanding this complex process, as the considerable 601 diversity in exercise regimens and post-exercise collection sample times utilized by researchers 602 limits the consolidation of knowledge across studies. As researchers take advantage of current 603 genomic, proteomic and bioinformatics tools, we will begin to visualize the patterns of gene 604 and protein expression changes that are associated with the angiogenic process, rather than 
605 simply describing the regulation of factors individually. This type of approach is necessary to be 606 able to construct a comprehensive framework that delineates the regulatory control of skeletal 607 muscle angiogenesis. Such knowledge then can be applied to identify potential biomarkers that 608 stratify individuals' 'angiogenic capacity', and to optimize exercise modalities that elicit capillary 609 growth within healthy individuals and patient populations.

610

\section{Acknowledgements:}

612 TLH is the recipient of the 2013 APMN President's Award Lecture (Canadian Society for Exercise 613 Physiology). TLH's research is funded by NSERC, HSF and CIHR. EN received funding from OGS 614 and NSERC PGS-A graduate scholarships.

615

616 Conflict of Interest:

617 Authors have no conflict of interest to report. 


\section{References}

619 Adams, J.C. 1997. Thrombospondin-1. Int. J. Biochem. Cell Biol. 29(6): 861-865.

620 Amaral, S.L., Linderman, J.R., Morse, M.M., and Greene, A.S. 2001a. Angiogenesis induced by electrical

621 stimulation is mediated by angiotensin II and VEGF. Microcirculation 8(1): 57-67.

622 Amaral, S.L., Papanek, P.E., and Greene, A.S. 2001b. Angiotensin II and VEGF are involved in

623 angiogenesis induced by short-term exercise training. Am. J. Physiol. Heart Circ. Physiol. 281(3): H11636241169.

625 Ameln, H. 2005. Physiological activation of hypoxia inducible factor-1 in human skeletal muscle. FASEB J. 626 19(8):1009-1011. doi: 10.1096/fj.04-2304fje.

627 Andersen, P. 1975. Capillary density in skeletal muscle of man. Acta Physiol. Scand. 95(2): 203-205. doi:

628 10.1111/j.1748-1716.1975.tb10043.x.

629 Andersen, P., and Henriksson, J. 1977. Capillary supply of the quadriceps femoris muscle of man:

630 adaptive response to exercise. J. Physiol. 270(3): 677-690.

631 Andersson, U., Sander, B., Andersson, J., and Möller, G. 1988. Concomitant production of different 632 Iymphokines in activated T cells. Eur. J. Immunol. 18(12): 2081-2084. doi: 10.1002/eji.1830181232.

633 Arany, Z., Foo, S.Y., Ma, Y., Ruas, J.L., Bommi-Reddy, A., Girnun, G., et al. 2008. HIF-independent 634 regulation of VEGF and angiogenesis by the transcriptional coactivator PGC-1alpha. Nature 451(7181): 635 1008-1012. doi: 10.1038/nature06613.

636 Askew, C.D., Green, S., Walker, P.J., Kerr, G.K., Green, A.A., Williams, A.D., et al. 2005. Skeletal muscle 637 phenotype is associated with exercise tolerance in patients with peripheral arterial disease. J. Vasc. Surg. 638 41(5): 802-807. doi: 10.1016/j.jvs.2005.01.037.

639 Augustin, H.G., Koh, G.Y., Thurston, G., and Alitalo, K. 2009. Control of vascular morphogenesis and 640 homeostasis through the angiopoietin-Tie system. Nat. Rev. Mol. Cell Biol. 10(3): 165-177. doi: $641 \quad 10.1038 / \mathrm{nrm} 2639$.

642 Azizi, P.M., Zyla, R.E., Guan, S., Wang, C., Liu, J., Bolz, S.S., et al. 2015. Clathrin-dependent entry and 643 vesicle-mediated exocytosis define insulin transcytosis across microvascular endothelial cells. Mol. Biol. 644 Cell 26(4): 740-750. doi: 10.1091/mbc.E14-08-1307.

645 Barrett, E.J., Eggleston, E.M., Inyard, A.C., Wang, H., Li, G., Chai, W., et al. 2009. The vascular actions of 646 insulin control its delivery to muscle and regulate the rate-limiting step in skeletal muscle insulin action. 647 Diabetologia 52(5): 752-764. doi: 10.1007/s00125-009-1313-z.

648 Barrett, E.J., Wang, H., Upchurch, C.T., and Liu, Z. 2011. Insulin regulates its own delivery to skeletal 649 muscle by feed-forward actions on the vasculature. Am. J. Physiol. Endocrinol. Metab. 301(2): E252-263. 650 doi: 10.1152/ajpendo.00186.2011. 
651 Baum, O., Da Silva-Azevedo, L., Willerding, G., Wöckel, A., Planitzer, G., Gossrau, R., et al. 2004.

652 Endothelial NOS is main mediator for shear stress-dependent angiogenesis in skeletal muscle after

653 prazosin administration. Am. J. Physiol. Heart Circ. Physiol. 287(5): H2300-2308. doi:

$654 \quad$ 10.1152/ajpheart.00065.2004.

655 Bellamy, L.M., Johnston, A.P.W., De Lisio, M., and Parise, G. 2010. Skeletal muscle-endothelial cell cross 656 talk through angiotensin II. Am. J. Physiol. Cell Physiol. 299(6): C1402-1408. doi:

657 10.1152/ajpcell.00306.2010.

658 Benedict, K.F., Coffin, G.S., Barrett, E.J., and Skalak, T.C. 2011. Hemodynamic systems analysis of 659 capillary network remodeling during the progression of type 2 diabetes. Microcirculation 18(1): 63-73. 660 doi: 10.1111/j.1549-8719.2010.00069.x.

661 Birot, O.J.G., Koulmann, N., Peinnequin, A., and Bigard, X.A. 2003. Exercise-induced expression of 662 vascular endothelial growth factor mRNA in rat skeletal muscle is dependent on fibre type. J. Physiol. 663 552(Pt 1): 213-221. doi: 10.1113/jphysiol.2003.043026.

664 De Bock, K., Georgiadou, M., and Carmeliet, P. 2013. Role of endothelial cell metabolism in vessel 665 sprouting. Cell Metab. 18(5): 634-647. doi: 10.1016/j.cmet.2013.08.001.

666 Bonnard, C., Durand, A., Peyrol, S., Chanseaume, E., Chauvin, M.A., Morio, B., et al. 2008. Mitochondrial 667 dysfunction results from oxidative stress in the skeletal muscle of diet-induced insulin-resistant mice. J. 668 Clin. Invest. 118(2): 789-800. doi: 10.1172/JCI32601.

669 Breen, E.C., Johnson, E.C., Wagner, H., Tseng, H.M., Sung, L.A., and Wagner, P.D. 1996. Angiogenic 670 growth factor mRNA responses in muscle to a single bout of exercise. J. Appl. Physiol. 81(1): 355-361.

671 Brew, K., and Nagase, H. 2010. The tissue inhibitors of metalloproteinases (TIMPs): an ancient family 672 with structural and functional diversity. Biochim. Biophys. Acta 1803(1): 55-71. doi:

673 10.1016/j.bbamcr.2010.01.003.

674 Brown, M.D., Cotter, M.A., Hudlická, O., and Vrbová, G. 1976. The effects of different patterns of muscle 675 activity on capillary density, mechanical properties and structure of slow and fast rabbit muscles. Pflüg. 676 Arch. Eur. J. Physiol. 361(3): 241-250.

677 Bruns, R.R., and Palade, G.E. 1968. Studies on blood capillaries. I. General organization of blood 678 capillaries in muscle. J. Cell Biol. 37(2): 244-276.

679 Butcher, J.T., Stanley, S.C., Brooks, S.D., Chantler, P.D., Wu, F., and Frisbee, J.C. 2014. Impact of 680 increased intramuscular perfusion heterogeneity on skeletal muscle microvascular hematocrit in the 681 metabolic syndrome. Microcirculation. 21(8): 677-687. doi: 10.1111/micc.12146.

682 Carroll, V.A., and Ashcroft, M. 2008. Regulation of angiogenic factors by HDM2 in renal cell carcinoma. 683 Cancer Res. 68(2): 545-552. doi: 10.1158/0008-5472.CAN-06-4738. 
684 Carrow, R.E., Brown, R.E., and Van Huss, W.D. 1967. Fiber sizes and capillary to fiber ratios in skeletal 685 muscle of exercised rats. Anat. Rec. 159(1): 33-39. doi: 10.1002/ar.1091590106.

686

687

688

689

690

691

692

693

694

695

696

697

698

699

700

701

702

703

704

705

706

707

708

709

710

711

712

713

714

715

716

717

Chang, H., Shyu, K.G., Wang, B.W., and Kuan, P. 2003. Regulation of hypoxia-inducible factor-1alpha by cyclical mechanical stretch in rat vascular smooth muscle cells. Clin. Sci. Lond. Engl. 1979 105(4): 447456. doi: 10.1042/CS20030088.

Chen, H., Herndon, M.E., and Lawler, J. 2000. The cell biology of thrombospondin-1. Matrix Biol. J. Int. Soc. Matrix Biol. 19(7): 597-614.

Cherwek, D.H., Hopkins, M.B., Thompson, M.J., Annex, B.H., and Taylor, D.A. 2000. Fiber type-specific differential expression of angiogenic factors in response to chronic hindlimb ischemia. Am. J. Physiol. Heart Circ. Physiol. 279(3): H932-938.

Chinsomboon, J., Ruas, J., Gupta, R.K., Thom, R., Shoag, J., Rowe, G.C., Sawada, N., et al. 2009. The transcriptional coactivator PGC-1alpha mediates exercise-induced angiogenesis in skeletal muscle. Proc. Natl. Acad. Sci. U. S. A. 106(50): 21401-21406. doi: 10.1073/pnas.0909131106.

Chu, L.H., Vijay, C.G., Annex, B.H., Bader, J.S., and Popel, A.S. 2015. PADPIN: Protein-Protein Interaction Networks of Angiogenesis, Arteriogenesis, and Inflammation in Peripheral Arterial Disease. Physiol. Genomics. doi: 10.1152/physiolgenomics.00125.2014.

Clark, E.R. 1918. Studies on the growth of blood-vessels in the tail of the frog larva?by observation and experiment on the living animal. Am. J. Anat. 23(1): 37-88. doi: 10.1002/aja.1000230103.

Clark, E.R., and Clark, E.L. 1940. Microscopic observations on the extra-endothelial cells of living mammalian blood vessels. Am. J. Anat. 66(1): 1-49. doi: 10.1002/aja.1000660102.

Cotter, M., Hudlická, O., Pette, D., Staudte, H., and Vrbová, G. 1973. Changes of capillary density and enzyme pattern in fast rabbit muscles during long-term stimulation. J. Physiol. 230(1): 34P-35P.

Couffinhal, T., Silver, M., Zheng, L.P., Kearney, M., Witzenbichler, B., and Isner, J.M. 1998. Mouse model of angiogenesis. Am. J. Pathol. 152(6): 1667-1679.

Dodd, T., Wiggins, L., Hutcheson, R., Smith, E., Musiyenko, A., Hysell, B., et al. 2013. Impaired Coronary Collateral Growth in the Metabolic Syndrome Is in Part Mediated by Matrix Metalloproteinase 12Dependent Production of Endostatin and Angiostatin. Arterioscler. Thromb. Vasc. Biol. 33(6): 13391349. doi: 10.1161/ATVBAHA.113.301533.

Duscha, B.D., Robbins, J.L., Jones, W.S., Kraus, W.E., Lye, R.J., Sanders, J.M., et al. 2011. Angiogenesis in skeletal muscle precede improvements in peak oxygen uptake in peripheral artery disease patients.

Arterioscler. Thromb. Vasc. Biol. 31(11): 2742-2748. doi: 10.1161/ATVBAHA.111.230441.

Ebrahimian, T.G., Heymes, C., You, D., Blanc-Brude, O., Mees, B., Waeckel, L., et al. 2006. NADPH oxidase-derived overproduction of reactive oxygen species impairs postischemic neovascularization in mice with type 1 diabetes. Am. J. Pathol. 169(2): 719-728. doi: 10.2353/ajpath.2006.060042. 
718 Egginton, S. 2009. Invited review: activity-induced angiogenesis. Pflüg. Arch. Eur. J. Physiol. 457(5): 963719 977. doi: 10.1007/s00424-008-0563-9.

720 Egginton, S. 2011. Physiological factors influencing capillary growth. Acta Physiol. Oxf. Engl. 202(3): 225721 239. doi: 10.1111/j.1748-1716.2010.02194.x.

723

Egginton, S., and Gaffney, E. 2010. Tissue capillary supply--it's quality not quantity that counts! Exp.

724 Physiol. 95(10): 971-979. doi: 10.1113/expphysiol.2010.053421.

725

Egginton, S., Hudlická, O., Brown, M.D., Walter, H., Weiss, J.B., and Bate, A. 1998. Capillary growth in

726 relation to blood flow and performance in overloaded rat skeletal muscle. J. Appl. Physiol. 85(6): 20252032.

727

Egginton, S., Zhou, A.L., Brown, M.D., and Hudlická, O. 2001. Unorthodox angiogenesis in skeletal

728 muscle. Cardiovasc. Res. 49(3): 634-646.

Eijkelenboom, A., and Burgering, B.M.T. 2013. FOXOs: signalling integrators for homeostasis maintenance. Nat. Rev. Mol. Cell Biol. 14(2): 83-97. doi: 10.1038/nrm3507. oxygen supply to skeletal muscle of prediabetic ZDF rats. Am. J. Physiol. Heart Circ. Physiol. 298(6): H1661-1670. doi: 10.1152/ajpheart.01239.2009. length on total capillary length in skeletal muscle: in vivo evidence for longitudinal stretching of capillaries. Microvasc. Res. 40(1): 63-72.

737 Emanueli, C., Caporali, A., Krankel, N., Cristofaro, B., Van Linthout, S., and Madeddu, P. 2007. Type-2 738 diabetic Lepr $(\mathrm{db} / \mathrm{db})$ mice show a defective microvascular phenotype under basal conditions and an 739 impaired response to angiogenesis gene therapy in the setting of limb ischemia. Front. Biosci. J. Virtual 740 Libr. 12: 2003-2012.

741 Fagiani, E., Christofori, G. 2013. Angiopoietins in angiogenesis. Cancer Lett. 328(1): 18-26. doi: $742 \quad 10.1016 /$ j.canlet.2012.08.018.

743 Favier, J., Germain, S., Emmerich, J., Corvol, P., and Gasc, J.M. 2005. Critical overexpression of 744 thrombospondin 1 in chronic leg ischaemia. J. Pathol. 207(3): 358-366. doi: 10.1002/path.1833.

745 Faye, C., Moreau, C., Chautard, E., Jetne, R., Fukai, N., Ruggiero, F., et al. 2009. Molecular interplay 746 between endostatin, integrins, and heparan sulfate. J. Biol. Chem. 284(33): 22029-22040. doi: $747 \quad 10.1074 / j b c . M 109.002840$.

748 Ferreras, M., Felbor, U., Lenhard, T., Olsen, B.R., and Delaissé, J. 2000. Generation and degradation of 749 human endostatin proteins by various proteinases. FEBS Lett. 486(3): 247-251. 
750

751

752

753

754

755

756

757

758

759

760

761

762

763

764

765

766

767

768

769

770

771

772

773

774

775

776

777

778

779

780

781

Fischer, C., Schneider, M., and Carmeliet, P. 2006. Principles and therapeutic implications of angiogenesis, vasculogenesis and arteriogenesis. Handb. Exp. Pharmacol. (176 Pt 2): 157-212.

Folkman, J. 1996. Endogenous inhibitors of angiogenesis. Harvey Lect. 92: 65-82.

Forder, J.P., Munzenmaier, D.H., and Greene, A.S. 2005. Angiogenic protection from focal ischemia with angiotensin II type 1 receptor blockade in the rat. Am. J. Physiol. Heart Circ. Physiol. 288(4): H19891996. doi: 10.1152/ajpheart.00839.2004.

Förstermann, U., and Sessa, W.C. 2012. Nitric oxide synthases: regulation and function. Eur. Heart J. 33(7): 829-837, 837a-837d. doi: 10.1093/eurheartj/ehr304.

Fridlyand, L.E., and Philipson, L.H. 2006. Reactive species and early manifestation of insulin resistance in type 2 diabetes. Diabetes Obes. Metab. 8(2): 136-145. doi: 10.1111/j.1463-1326.2005.00496.x.

Frisbee, J.C. 2007. Obesity, insulin resistance, and microvessel density. Microcirculation. 14(4-5): 289298. doi: 10.1080/10739680701282945.

Gavin, T.P., Stallings, H.W., Zwetsloot, K.A., Westerkamp, L.M., Ryan, N.A., Moore, R.A., et al. Lower capillary density but no difference in VEGF expression in obese vs. lean young skeletal muscle in humans. J. Appl. Physiol. 98(1): 315-321. doi: 10.1152/japplphysiol.00353.2004.

Gee, E., Milkiewicz, M., and Haas, T.L. 2010. p38 MAPK activity is stimulated by vascular endothelial growth factor receptor 2 activation and is essential for shear stress-induced angiogenesis. J. Cell. Physiol. 222(1): 120-126. doi: 10.1002/jcp.21924.

Geudens, I., and Gerhardt, H. 2011. Coordinating cell behaviour during blood vessel formation. Development 138(21): 4569-4583. doi: 10.1242/dev.062323.

Gimbrone, M.A., Leapman, S.B., Cotran, R.S., and Folkman, J. 1972. Tumor dormancy in vivo by prevention of neovascularization. J. Exp. Med. 136(2): 261-276.

Goodwill, A.G., and Frisbee, J.C. 2012. Oxidant stress and skeletal muscle microvasculopathy in the metabolic syndrome. Vascul. Pharmacol. 57(5-6): 150-159. doi: 10.1016/j.vph.2012.07.002.

Goodwill, A.G., James, M.E., and Frisbee, J.C. 2008. Increased vascular thromboxane generation impairs dilation of skeletal muscle arterioles of obese Zucker rats with reduced oxygen tension. Am. J. Physiol. Heart Circ. Physiol. 295(4): H1522-1528. doi: 10.1152/ajpheart.00596.2008.

Gorman, J.L., Liu, S.T.K., Slopack, D., Shariati, K., Hasanee, A., Olenich, S., et al. 2014. Angiotensin II evokes angiogenic signals within skeletal muscle through co-ordinated effects on skeletal myocytes and endothelial cells. PloS One 9(1): e85537. doi: 10.1371/journal.pone.0085537.

Gustafsson, T. 2011. Vascular remodelling in human skeletal muscle. Biochem. Soc. Trans. 39(6): 16281632. doi: 10.1042/BST20110720. 
Gustafsson, T., Ameln, H., Fischer, H., Sundberg, C.J., Timmons, J.A., and Jansson, E. 2005. VEGF-A splice variants and related receptor expression in human skeletal muscle following submaximal exercise. J. Appl. Physiol. 98(6): 2137-2146. doi: 10.1152/japplphysiol.01402.2004.

Gustafsson, T., Puntschart, A., Kaijser, L., Jansson, E., and Sundberg, C.J. 1999. Exercise-induced expression of angiogenesis-related transcription and growth factors in human skeletal muscle. Am. J. Physiol. 276(2 Pt 2): H679-685.

Gustafsson, T., Rundqvist, H., Norrbom, J., Rullman, E., Jansson, E., and Sundberg, C.J. 2007. The influence of physical training on the angiopoietin and VEGF-A systems in human skeletal muscle. J. Appl. Physiol. 103(3): 1012-1020. doi: 10.1152/japplphysiol.01103.2006.

Haas, T.L., Lloyd, P.G., Yang, H.T., and Terjung, R.L. 2012. Exercise training and peripheral arterial disease. Compr. Physiol. 2(4): 2933-3017. doi: 10.1002/cphy.c110065.

Haas, T.L., and Madri, J.A. 1999. Extracellular matrix-driven matrix metalloproteinase production in endothelial cells: implications for angiogenesis. Trends Cardiovasc. Med. 9(3-4): 70-77.

Haas, T.L., Milkiewicz, M., Davis, S.J., Zhou, A.L., Egginton, S., Brown, M.D., et al. 2000. Matrix metalloproteinase activity is required for activity-induced angiogenesis in rat skeletal muscle. Am. J. Physiol.Heart Circ. Physiol. 279(4): H1540-H1547.

Hazarika, S., Dokun, A.O., Li, Y., Popel, A.S., Kontos, C.D., and Annex, B.H. 2007. Impaired angiogenesis after hindlimb ischemia in type 2 diabetes mellitus: differential regulation of vascular endothelial growth factor receptor 1 and soluble vascular endothelial growth factor receptor 1. Circ. Res. 101(9): 948-956. doi: 10.1161/CIRCRESAHA.107.160630.

Hellsten, Y., Rufener, N., Nielsen, J.J., Høier, B., Krustrup, P., and Bangsbo, J. 2008. Passive leg movement enhances interstitial VEGF protein, endothelial cell proliferation, and eNOS mRNA content in human skeletal muscle. Am. J. Physiol. Regul. Integr. Comp. Physiol. 294(3): R975-982. doi: 10.1152/ajpregu.00677.2007.

Henriksson, J., Nygaard, E., Andersson, J., and Eklöf, B. 1980. Enzyme activities, fibre types and capillarization in calf muscles of patients with intermittent claudication. Scand. J. Clin. Lab. Invest. 40(4): 361-369.

Hermansen, L., and Wachtlova, M. 1971. Capillary density of skeletal muscle in well-trained and untrained men. J. Appl. Physiol. 30(6): 860-863.

Hoier, B., and Hellsten, Y. 2014. Exercise-induced capillary growth in human skeletal muscle and the dynamics of VEGF. Microcirculation 21(4): 301-314. doi: 10.1111/micc.12117.

Hoier, B., Nordsborg, N., Andersen, S., Jensen, L., Nybo, L., Bangsbo, J., et al. 2012. Pro- and antiangiogenic factors in human skeletal muscle in response to acute exercise and training. J. Physiol. 590(Pt 3): 595-606. doi: 10.1113/jphysiol.2011.216135. 
816 Høier, B., Olsen, K., Nyberg, M., Bangsbo, J., and Hellsten, Y. 2010. Contraction-induced secretion of 817 VEGF from skeletal muscle cells is mediated by adenosine. Am. J. Physiol. Heart Circ. Physiol. 299(3):

818 H857-862. doi: 10.1152/ajpheart.00082.2010.

819 Hoier, B., Prats, C., Qvortrup, K., Pilegaard, H., Bangsbo, J., and Hellsten, Y. 2013a. Subcellular

820 localization and mechanism of secretion of vascular endothelial growth factor in human skeletal muscle.

821 FASEB J. 27(9): 3496-3504. doi: 10.1096/fj.12-224618.

822 Hoier, B., Walker, M., Passos, M., Walker, P.J., Green, A., Bangsbo, J., et al. 2013b. Angiogenic response 823 to passive movement and active exercise in individuals with peripheral arterial disease. J. Appl. Physiol. 824 115(12): 1777-1787. doi: 10.1152/japplphysiol.00979.2013.

825 Holly, R.G., Barnett, J.G., Ashmore, C.R., Taylor, R.G., and Molé, P.A. 1980. Stretch-induced growth in 826 chicken wing muscles: a new model of stretch hypertrophy. Am. J. Physiol. 238(1): C62-71.

827 Hudlicka, O. 1998. Is physiological angiogenesis in skeletal muscle regulated by changes in 828 microcirculation? Microcirculation 1994 5(1): 7-23.

829 Hudlická, O., Brown, M.D., and Silgram, H. 2000. Inhibition of capillary growth in chronically stimulated 830 rat muscles by N(G)-nitro-I-arginine, nitric oxide synthase inhibitor. Microvasc. Res. 59(1): 45-51. doi: $831 \quad 10.1006 / m v r e .1999 .2193$.

832 Imoukhuede, P.I., Dokun, A.O., Annex, B.H., and Popel, A.S. 2013. Endothelial cell-by-cell profiling 833 reveals the temporal dynamics of VEGFR1 and VEGFR2 membrane localization after murine hindlimb 834 ischemia. Am. J. Physiol. Heart Circ. Physiol. 304(8): H1085-1093. doi: 10.1152/ajpheart.00514.2012.

835 Iruela-Arispe, M.L., Luque, A., and Lee, N. 2004. Thrombospondin modules and angiogenesis. Int. J. 836 Biochem. Cell Biol. 36(6): 1070-1078. doi: 10.1016/j.biocel.2004.01.025.

837 Ispanovic, E., and Haas, T.L. 2006. JNK and PI3K differentially regulate MMP-2 and MT1-MMP mRNA and 838 protein in response to actin cytoskeleton reorganization in endothelial cells. Am. J. Physiol. Cell Physiol. 839 291(4): C579-588. doi: 10.1152/ajpcell.00300.2005.

840 James, N.T. 1981. A stereological analysis of capillaries in normal and hypertrophic muscle. J. Morphol. 841 168(1): 43-49. doi: 10.1002/jmor.1051680106.

842 Jansson, E., Johansson, J., Sylvén, C., and Kaijser, L. 1988. Calf muscle adaptation in intermittent 843 claudication. Side-differences in muscle metabolic characteristics in patients with unilateral arterial 844 disease. Clin. Physiol. Oxf. Engl. 8(1): 17-29.

845 Jude, E.B., Eleftheriadou, I., and Tentolouris, N. 2010. Peripheral arterial disease in diabetes--a review. 846 Diabet. Med. J. Br. Diabet. Assoc. 27(1): 4-14. doi: 10.1111/j.1464-5491.2009.02866.x.

847 Keller, P., Vollaard, N.B.J., Gustafsson, T., Gallagher, I.J., Sundberg, C.J., Rankinen, T., et al. A 848 transcriptional map of the impact of endurance exercise training on skeletal muscle phenotype. J. Appl. 849 Physiol. 110(1): 46-59. doi: 10.1152/japplphysiol.00634.2010. 
850 Kivelä, R., Silvennoinen, M., Lehti, M., Jalava, S., Vihko, V., and Kainulainen, H. 2008. Exercise-induced 851 expression of angiogenic growth factors in skeletal muscle and in capillaries of healthy and diabetic 852 mice. Cardiovasc. Diabetol. 7: 13. doi: 10.1186/1475-2840-7-13.

853 Krogh, A. 1919. The number and distribution of capillaries in muscles with calculations of the oxygen 854 pressure head necessary for supplying the tissue. J. Physiol. 52(6): 409-415.

855 Lee, S., Jilani, S.M., Nikolova, G.V., Carpizo, D., and Iruela-Arispe, M.L. 2005. Processing of VEGF-A by 856 matrix metalloproteinases regulates bioavailability and vascular patterning in tumors. J. Cell Biol. 169(4): 857 681-691. doi: 10.1083/jcb.200409115.

858 Lillioja, S., Young, A.A., Culter, C.L., Ivy, J.L., Abbott, W.G., Zawadzki, J.K., et al. 1987. Skeletal muscle 859 capillary density and fiber type are possible determinants of in vivo insulin resistance in man. J. Clin. 860 Invest. 80(2): 415-424. doi: 10.1172/JCl113088.

861 Lindholm, M.E., Fischer, H., Poellinger, L., Johnson, R.S., Gustafsson, T., Sundberg, C.J., et al. 2014 a.

862 Negative regulation of HIF in skeletal muscle of elite endurance athletes: a tentative mechanism 863 promoting oxidative metabolism. Am. J. Physiol. Regul. Integr. Comp. Physiol. 307(3): R248-255. doi:

864 10.1152/ajpregu.00036.2013.

865 Lindholm, M.E., Marabita, F., Gomez-Cabrero, D., Rundqvist, H., Ekström, T.J., Tegnér, J., et al. 2014b. An 866 integrative analysis reveals coordinated reprogramming of the epigenome and the transcriptome in 867 human skeletal muscle after training. Epigenetics 9(12): 1557-1569. doi:

868 10.4161/15592294.2014.982445.

869 Lloyd, P.G., Prior, B.M., Yang, H.T., and Terjung, R.L. 2003. Angiogenic growth factor expression in rat 870 skeletal muscle in response to exercise training. Am. J. Physiol. Heart Circ. Physiol. 284(5): H1668-1678. 871 doi: 10.1152/ajpheart.00743.2002.

872 Lundby, C., Gassmann, M., and Pilegaard, H. 2006. Regular endurance training reduces the exercise 873 induced HIF-1alpha and HIF-2alpha mRNA expression in human skeletal muscle in normoxic conditions. 874 Eur. J. Appl. Physiol. 96(4): 363-369. doi: 10.1007/s00421-005-0085-5.

875 Maharaj, A.S.R., Saint-Geniez, M., Maldonado, A.E., and D'Amore, P.A. 2006. Vascular endothelial 876 growth factor localization in the adult. Am. J. Pathol. 168(2): 639-648. doi: 10.2353/ajpath.2006.050834.

877 Malek, M.H., and Olfert, I.M. 2009. Global deletion of thrombospondin-1 increases cardiac and skeletal 878 muscle capillarity and exercise capacity in mice. Exp. Physiol. 94(6): 749-760. doi:

879 10.1113/expphysiol.2008.045989.

880 Mandel, E.R., Uchida, C., and Haas, T.L. 2014. Regulation of Proteolysis in Vascular Remodeling. In Role 881 of Proteases in Cellular Dysfunction. Edited by N.S. Dhalla and S. Chakraborti. Springer New York, New 882 York, NY. pp. 295-319. Available from http://link.springer.com/10.1007/978-1-4614-9099-9_16. 
883

884

885

886

887

888

889

890

891

892

893

894

895

896

897

898

899

900

901

902

903

904

905

906

907

908

909

910

911

912

913

914

915

916

Mandriota, S.J., and Pepper, M.S. 1998. Regulation of angiopoietin-2 mRNA levels in bovine microvascular endothelial cells by cytokines and hypoxia. Circ. Res. 83(8): 852-859.

Mårin, P., Andersson, B., Krotkiewski, M., and Björntorp, P. 1994. Muscle fiber composition and capillary density in women and men with NIDDM. Diabetes Care 17(5): 382-386.

Mason, S.D., Rundqvist, H., Papandreou, I., Duh, R., McNulty, W.J., Howlett, R.A., et al. 2007. HIF-1alpha in endurance training: suppression of oxidative metabolism. Am. J. Physiol. Regul. Integr. Comp. Physiol. 293(5): R2059-2069. doi: 10.1152/ajpregu.00335.2007.

Milkiewicz, M., Doyle, J.L., Fudalewski, T., Ispanovic, E., Aghasi, M., and Haas, T.L. 2007a. HIF-1alpha and HIF-2alpha play a central role in stretch-induced but not shear-stress-induced angiogenesis in rat skeletal muscle. J. Physiol. 583(Pt 2): 753-766. doi: 10.1113/jphysiol.2007.136325.

Milkiewicz, M., Hudlicka, O., Shiner, R., Egginton, S., and Brown, M.D. 2006a. Vascular endothelial growth factor mRNA and protein do not change in parallel during non-inflammatory skeletal muscle ischaemia in rat. J. Physiol. 577(Pt 2): 671-678. doi: 10.1113/jphysiol.2006.113357.

Milkiewicz, M., Hudlicka, O., Verhaeg, J., Egginton, S., and Brown, M.D. 2003. Differential expression of Flk-1 and Flt-1 in rat skeletal muscle in response to chronic ischaemia: favourable effect of muscle activity. Clin. Sci. 105(4): 473-482. doi: 10.1042/CS20030035.

Milkiewicz, M., Kelland, C., Colgan, S., and Haas, T.L. 2006b. Nitric oxide and p38 MAP kinase mediate shear stress-dependent inhibition of MMP-2 production in microvascular endothelial cells. J. Cell. Physiol. 208(1): 229-237. doi: 10.1002/jcp.20658.

Milkiewicz, M., Mohammadzadeh, F., Ispanovic, E., Gee, E., and Haas, T.L. 2007b. Static strain stimulates expression of matrix metalloproteinase-2 and VEGF in microvascular endothelium via JNK- and ERKdependent pathways. J. Cell. Biochem. 100(3): 750-761. doi: 10.1002/jcb.21055.

Milkiewicz, M., Roudier, E., Doyle, J.L., Trifonova, A., Birot, O., and Haas, T.L. 2011. Identification of a mechanism underlying regulation of the anti-angiogenic forkhead transcription factor FoxO1 in cultured endothelial cells and ischemic muscle. Am. J. Pathol. 178(2): 935-944. doi:

10.1016/j.ajpath.2010.10.042.

Milkiewicz, M., Uchida, C., Gee, E., Fudalewski, T., and Haas, T.L. 2008. Shear stress-induced Ets-1 modulates protease inhibitor expression in microvascular endothelial cells. J. Cell. Physiol. 217(2): 502510. doi: 10.1002/jcp.21526.

Molé, P.A., Chung, Y., Tran, T.K., Sailasuta, N., Hurd, R., and Jue, T. 1999. Myoglobin desaturation with exercise intensity in human gastrocnemius muscle. Am. J. Physiol. 277(1 Pt 2): R173-180.

Morbidelli, L., Chang, C.H., Douglas, J.G., Granger, H.J., Ledda, F., and Ziche, M. 1996. Nitric oxide mediates mitogenic effect of VEGF on coronary venular endothelium. Am. J. Physiol. 270(1 Pt 2): H411415. 
917 Morbidelli, L., Donnini, S., and Ziche, M. 2003. Role of nitric oxide in the modulation of angiogenesis. 918 Curr. Pharm. Des. 9(7): 521-530.

919 Munzenmaier, D.H., and Greene, A.S. 2006. Chronic angiotensin II AT1 receptor blockade increases 920 cerebral cortical microvessel density. Am. J. Physiol. Heart Circ. Physiol. 290(2): H512-516. doi: 921 10.1152/ajpheart.01136.2004.

922 Murphy-Ullrich, J.E., and Poczatek, M. 2000. Activation of latent TGF-beta by thrombospondin-1:

923 mechanisms and physiology. Cytokine Growth Factor Rev. 11(1-2): 59-69.

924 Myrhage, R., and Hudlická, O. 1978. Capillary growth in chronically stimulated adult skeletal muscle as 925 studied by intravital microscopy and histological methods in rabbits and rats. Microvasc. Res. 16(1): 7392690.

927 Neufeld, G., Cohen, T., Gitay-Goren, H., Poltorak, Z., Tessler, S., Sharon, R., et al. 1996. Similarities and 928 differences between the vascular endothelial growth factor (VEGF) splice variants. Cancer Metastasis 929 Rev. 15(2): 153-158.

930 Norgren, L., Hiatt, W.R., Dormandy, J.A., Nehler, M.R., Harris, K.A., Fowkes, F.G.R., et al. 2007. Inter931 Society Consensus for the Management of Peripheral Arterial Disease (TASC II). J. Vasc. Surg. 45 Suppl S: 932 S5-67. doi: 10.1016/j.jvs.2006.12.037.

933 Norrbom, J., Sundberg, C.J., Ameln, H., Kraus, W.E., Jansson, E., and Gustafsson, T. 2004. PGC-1alpha 934 mRNA expression is influenced by metabolic perturbation in exercising human skeletal muscle. J. Appl. 935 Physiol. 96(1): 189-194. doi: 10.1152/japplphysiol.00765.2003.

936 Novielli, N.M., and Jackson, D.N. 2014. Contraction-evoked vasodilation and functional hyperaemia are 937 compromised in branching skeletal muscle arterioles of young pre-diabetic mice. Acta Physiol. Oxf. Engl. 938 211(2): 371-384. doi: 10.1111/apha.12297.

939 Oh, H., Takagi, H., Suzuma, K., Otani, A., Matsumura, M., and Honda, Y. 1999. Hypoxia and vascular 940 endothelial growth factor selectively up-regulate angiopoietin-2 in bovine microvascular endothelial 941 cells. J. Biol. Chem. 274(22): 15732-15739.

942 Olenich, S.A., Gutierrez-Reed, N., Audet, G.N., and Olfert, I.M. 2013. Temporal response of positive and 943 negative regulators in response to acute and chronic exercise training in mice. J. Physiol. 591(Pt 20): 944 5157-5169. doi: 10.1113/jphysiol.2013.254979.

945 Olfert, I.M., and Birot, O. 2011. Importance of Anti-angiogenic Factors in the Regulation of Skeletal 946 Muscle Angiogenesis: Physical Activity and Inhibitors of Angiogenesis. Microcirculation 18(4): 316-330. 947 doi: 10.1111/j.1549-8719.2011.00092.x.

948 Olfert, I.M., Howlett, R.A., Wagner, P.D., and Breen, E.C. 2010. Myocyte vascular endothelial growth 949 factor is required for exercise-induced skeletal muscle angiogenesis. Am. J. Physiol. Regul. Integr. Comp. 950 Physiol. 299(4): R1059-1067. doi: 10.1152/ajpregu.00347.2010. 
951 O’Reilly, M.S., Boehm, T., Shing, Y., Fukai, N., Vasios, G., Lane, W.S., et al. 1997. Endostatin: an

952 endogenous inhibitor of angiogenesis and tumor growth. Cell 88(2): 277-285.

953 O’Reilly, M.S., Holmgren, L., Shing, Y., Chen, C., Rosenthal, R.A., Moses, M., et al. 1994. Angiostatin: a

954 novel angiogenesis inhibitor that mediates the suppression of metastases by a Lewis lung carcinoma.

955 Cell 79(2): 315-328.

956 Otani, A., Takagi, H., Oh, H., Koyama, S., and Honda, Y. 2001. Angiotensin II induces expression of the

957 Tie2 receptor ligand, angiopoietin-2, in bovine retinal endothelial cells. Diabetes 50(4): 867-875.

958 Padilla, D.J., McDonough, P., Behnke, B.J., Kano, Y., Hageman, K.S., Musch, T.I., et al. 2006. Effects of 959 Type II diabetes on capillary hemodynamics in skeletal muscle. Am. J. Physiol. Heart Circ. Physiol. 291(5):

960 H2439-2444. doi: 10.1152/ajpheart.00290.2006.

961 Paik, J.H., Kollipara, R., Chu, G., Ji, H., Xiao, Y., Ding, Z., et al. 2007. FoxOs are lineage-restricted 962 redundant tumor suppressors and regulate endothelial cell homeostasis. Cell 128(2): 309-323. doi:

963 10.1016/j.cell.2006.12.029.

964 Papapetropoulos, A., Desai, K.M., Rudic, R.D., Mayer, B., Zhang, R., Ruiz-Torres, et al. 1997. Nitric oxide 965 synthase inhibitors attenuate transforming-growth-factor-beta 1-stimulated capillary organization in 966 vitro. Am. J. Pathol. 150(5): 1835-1844.

967 Pasarica, M., Sereda, O.R., Redman, L.M., Albarado, D.C., Hymel, D.T., Roan, L.E., et al. 2009. Reduced 968 Adipose Tissue Oxygenation in Human Obesity Evidence for Rarefaction, Macrophage Chemotaxis, and 969 Inflammation Without an Angiogenic Response. Diabetes 58(3): 718-725. doi: 10.2337/db08-1098.

970 Patan, S., Haenni, B., and Burri, P.H. 1993. Evidence for intussusceptive capillary growth in the chicken 971 chorio-allantoic membrane (CAM). Anat. Embryol. (Berl.) 187(2): 121-130.

972 Plein, A., Fantin, A., and Ruhrberg, C. 2014. Neuropilin regulation of angiogenesis, arteriogenesis, and 973 vascular permeability. Microcirc. N. Y. N 1994 21(4): 315-323. doi: 10.1111/micc.12124.

974 Plyley, M.J. 1990. Quantifying the capillary supply of skeletal muscle. Can. J. Sport Sci. J. Can. Sci. Sport 975 15(2): 84-85.

976 Plyley, M.J., and Groom, A.C. 1975. Geometrical distribution of capillaries in mammalian striated muscle. 977 Am. J. Physiol. 228(5): 1376-1383.

978 Potente, M., Urbich, C., Sasaki, K., Hofmann, W.K., Heeschen, C., Aicher, A., et al. 2005. Involvement of 979 Foxo transcription factors in angiogenesis and postnatal neovascularization. J. Clin. Invest. 115(9): 2382$980 \quad$ 2392. doi: $10.1172 / \mathrm{JCl} 23126$.

981 Pugh, C.W., and Ratcliffe, P.J. 2003. Regulation of angiogenesis by hypoxia: role of the HIF system. Nat. 982 Med. 9(6): 677-684. doi: 10.1038/nm0603-677. 
Resovi, A., Pinessi, D., Chiorino, G., and Taraboletti, G. 2014. Current understanding of the thrombospondin-1 interactome. Matrix Biol. 37: 83-91. doi: 10.1016/j.matbio.2014.01.012.

Richard, D.E., Berra, E., and Pouyssegur, J. 2000. Nonhypoxic pathway mediates the induction of hypoxia-inducible factor 1alpha in vascular smooth muscle cells. J. Biol. Chem. 275(35): 26765-26771. doi: 10.1074/jbc.M003325200.

Richardson, R.S., Noyszewski, E.A., Kendrick, K.F., Leigh, J.S., and Wagner, P.D. 1995. Myoglobin 02 desaturation during exercise. Evidence of limited O2 transport. J. Clin. Invest. 96(4): 1916-1926. doi: 10.1172/JCI118237.

Richardson, R.S., Wagner, H., Mudaliar, S.R., Henry, R., Noyszewski, E.A., and Wagner, P.D. 1999. Human VEGF gene expression in skeletal muscle: effect of acute normoxic and hypoxic exercise. Am. J. Physiol. 277(6 Pt 2): H2247-2252.

Richardson, R.S., Wagner, H., Mudaliar, S.R., Saucedo, E., Henry, R., and Wagner, P.D. 2000. Exercise adaptation attenuates VEGF gene expression in human skeletal muscle. Am. J. Physiol. Heart Circ. Physiol. 279(2): H772-778.

Ries, C. 2014. Cytokine functions of TIMP-1. Cell. Mol. Life Sci. CMLS 71(4): 659-672. doi: 10.1007/s00018-013-1457-3.

Rivilis, I., Milkiewicz, M., Boyd, P., Goldstein, J., Brown, M.D., Egginton, S., et al. 2002. Differential involvement of MMP-2 and VEGF during muscle stretch- versus shear stress-induced angiogenesis. Am. J. Physiol. Heart Circ. Physiol. 283(4): H1430-1438. doi: 10.1152/ajpheart.00082.2002.

Robbins, J.L., Jones, W.S., Duscha, B.D., Allen, J.D., Kraus, W.E., Regensteiner, J.G., et al. 2011. Relationship between leg muscle capillary density and peak hyperemic blood flow with endurance capacity in peripheral artery disease. J. Appl. Physiol. 111(1): 81-86. doi: 10.1152/japplphysiol.00141.2011.

Romanul, F.C. 1964. Distribution of capillaries in relation to oxidative metabolism of skeletal muscle fibres. Nature 201: 307-308.

Roudier, E., Aiken, J., Slopack, D., Gouzi, F., Mercier, J., Haas, T.L., et al. 2013a. Novel perspective: exercise training stimulus triggers the expression of the oncoprotein human double minute- 2 in human skeletal muscle. Physiol. Rep. 1(2): e00028. doi: 10.1002/phy2.28.

Roudier, E., Forn, P., Perry, M.E., and Birot, O. 2012. Murine double minute-2 expression is required for capillary maintenance and exercise-induced angiogenesis in skeletal muscle. FASEB J. 26(11): 45304539. doi: 10.1096/fj.12-212720.

Roudier, E., Milkiewicz, M., Birot, O., Slopack, D., Montelius, A., Gustafsson, T., et al. Endothelial FoxO1 is an intrinsic regulator of thrombospondin 1 expression that restrains angiogenesis in ischemic muscle. Angiogenesis 16(4): 759-772. doi: 10.1007/s10456-013-9353-x. 
1017 Rullman, E., Norrbom, J., Strömberg, A., Wågsäter, D., Rundqvist, H., Haas, T., et al. 2009. Endurance 1018 exercise activates matrix metalloproteinases in human skeletal muscle. J. Appl. Physiol. 106(3): 804-812. 1019 doi: 10.1152/japplphysiol.90872.2008.

1020 Rullman, E., Rundqvist, H., Wågsäter, D., Fischer, H., Eriksson, P., Sundberg, C.J., et al. 2007. A single 1021 bout of exercise activates matrix metalloproteinase in human skeletal muscle. J. Appl. Physiol. 102(6): 1022 2346-2351. doi: 10.1152/japplphysiol.00822.2006.

1023 Semenza, G.L. 2014. Oxygen sensing, hypoxia-inducible factors, and disease pathophysiology. Annu. Rev. 1024 Pathol. 9: 47-71. doi: 10.1146/annurev-pathol-012513-104720.

1025

1026

1027

1028

1029

1030

1031

1032

1033

1034

1035

1036

1037

1038

1039

1040

1041

1042

1043

1044

1045

1046

1047

1048

1049

Sessa, W.C. 2009. Molecular control of blood flow and angiogenesis: role of nitric oxide. J. Thromb. Haemost. JTH 7 Suppl 1: 35-37. doi: 10.1111/j.1538-7836.2009.03424.x.

Al-Shammari, A.A., Gaffney, E.A., and Egginton, S. 2014. Modelling capillary oxygen supply capacity in mixed muscles: capillary domains revisited. J. Theor. Biol. 356: 47-61. doi: 10.1016/j.jtbi.2014.04.016.

Sherwood, L.M., Parris, E.E., and Folkman, J. 1971. Tumor Angiogenesis: Therapeutic Implications. N. Engl. J. Med. 285(21): 1182-1186. doi: 10.1056/NEJM197111182852108.

Shikatani, E.A., Trifonova, A., Mandel, E.R., Liu, S.T.K., Roudier, E., Krylova, A., et al. 2012. Inhibition of proliferation, migration and proteolysis contribute to corticosterone-mediated inhibition of angiogenesis. PloS One 7(10): e46625. doi: 10.1371/journal.pone.0046625.

Silverstein, R.L., Leung, L.L., and Nachman, R.L. 1986. Thrombospondin: a versatile multifunctional glycoprotein. Arterioscler. Dallas Tex 6(3): 245-253.

Simionescu, M., Simionescu, N., and Palade, G.E. 1974. Morphometric data on the endothelium of blood capillaries. J. Cell Biol. 60(1): 128-152.

Slopack, D., Roudier, E., Liu, S.T.K., Nwadozi, E., Birot, O., and Haas, T.L. 2014. Forkhead BoxO transcription factors restrain exercise-induced angiogenesis: FoxO proteins delay exercise-driven angiogenesis. J. Physiol. 592(18): 4069-4082. doi: 10.1113/jphysiol.2014.275867.

Sodha, N.R. 2008. Increased Antiangiogenic Protein Expression in the Skeletal Muscle of Diabetic Swine and Patients. Arch. Surg. 143(5): 463. doi: 10.1001/archsurg.143.5.463.

Solomon, T.P.J., Haus, J.M., Li, Y., and Kirwan, J.P. 2011. Progressive Hyperglycemia across the Glucose Tolerance Continuum in Older Obese Adults Is Related to Skeletal Muscle Capillarization and Nitric Oxide Bioavailability. J. Clin. Endocrinol. Metab. 96(5): 1377-1384. doi: 10.1210/jc.2010-2069.

Stanford, K.I., and Goodyear, L.J. 2014. Exercise and type 2 diabetes: molecular mechanisms regulating glucose uptake in skeletal muscle. Adv. Physiol. Educ. 38(4): 308-314. doi: 10.1152/advan.00080.2014.

Stetler-Stevenson, W.G. 2008. Tissue inhibitors of metalloproteinases in cell signaling:

metalloproteinase-independent biological activities. Sci. Signal. 1(27): re6. doi: 10.1126/scisignal.127re6. 
1050 Styp-Rekowska, B., Hlushchuk, R., Pries, A.R., and Djonov, V. 2011. Intussusceptive angiogenesis: pillars 1051 against the blood flow. Acta Physiol. Oxf. Engl. 202(3): 213-223. doi: 10.1111/j.1748-1716.2011.02321.x.

1052 Suhr, F., Brixius, K., and Bloch, W. 2009. Angiogenic and vascular modulation by extracellular matrix 1053 cleavage products. Curr. Pharm. Des. 15(4): 389-410.

1054 Thurston, G., and Daly, C. 2012. The complex role of angiopoietin-2 in the angiopoietin-tie signaling 1055 pathway. Cold Spring Harb. Perspect. Med. 2(9): a006550. doi: 10.1101/cshperspect.a006650.

1056

1057

1058

1059

1060

1061

1062

1063

1064

1065

1066

1067

1068

1069

1070

1071

1072

1073

1074

1075

1076

1077

1078

1079

1080

1081

Timmons, J.A., Jansson, E., Fischer, H., Gustafsson, T., Greenhaff, P.L., Ridden, J., et al. 2005. Modulation of extracellular matrix genes reflects the magnitude of physiological adaptation to aerobic exercise training in humans. BMC Biol. 3: 19. doi: 10.1186/1741-7007-3-19.

Troyanovsky, B., Levchenko, T., Månsson, G., Matvijenko, O., and Holmgren, L. 2001. Angiomotin: an angiostatin binding protein that regulates endothelial cell migration and tube formation. J. Cell Biol. 152(6): 1247-1254.

Uchida, C., and Haas, T.L. 2014. Endothelial cell TIMP-1 is upregulated by shear stress via Sp-1 and the TGFß1 signaling pathways. Biochem. Cell Biol. Biochim. Biol. Cell. 92(1): 77-83. doi: 10.1139/bcb-20130086.

Uchida, C., Nwadozi, E., Hasanee, A., Olenich, S., Olfert, I.M., and Haas, T.L. 2015. Muscle-derived vascular endothelial growth factor regulates microvascular remodelling in response to increased shear stress in mice. Acta Physiol. Oxf. Engl. 214(3): 349-360. doi: 10.1111/apha.12463.

Vempati, P., Popel, A.S., and Mac Gabhann, F. 2014. Extracellular regulation of VEGF: isoforms, proteolysis, and vascular patterning. Cytokine Growth Factor Rev. 25(1): 1-19. doi:

10.1016/j.cytogfr.2013.11.002.

Walther, T., Menrad, A., Orzechowski, H.D., Siemeister, G., Paul, M., and Schirner, M. 2003. Differential regulation of in vivo angiogenesis by angiotensin II receptors. FASEB J. 17(14): 2061-2067. doi: 10.1096/fj.03-0129com.

Williams, J.L., Cartland, D., Hussain, A., and Egginton, S. 2006. A differential role for nitric oxide in two forms of physiological angiogenesis in mouse. J. Physiol. 570(Pt 3): 445-454. doi:

10.1113/jphysiol.2005.095596.

Xiang, L., Dearman, J., Abram, S.R., Carter, C., and Hester, R.L. 2008. Insulin resistance and impaired functional vasodilation in obese Zucker rats. Am. J. Physiol. Heart Circ. Physiol. 294(4): H1658-1666. doi: 10.1152/ajpheart.01206.2007.

Yuan, H.T., Yand, S.P., and Woolf, A.S. 2000. Hypoxia up-regulates angiopoeitin-2, a Tie-2 ligand, in mouse mesangial cells. Kidney Int. 58(5): 1912-1919. doi:10.1111/j.1523-1755.2000.00363.x 
1082 Yun, S., Dardik, A., Haga, M., Yamashita, A., Yamaguchi, S., Koh, Y., et al. 2002. Transcription factor Sp1 1083 phosphorylation induced by shear stress inhibits membrane type 1-matrix metalloproteinase expression 1084 in endothelium. J. Biol. Chem. 277(38): 34808-34814. doi: 10.1074/jbc.M205417200.

1085 Zhou, A., Egginton, S., Hudlická, O., and Brown, M.D. 1998. Internal division of capillaries in rat skeletal 1086 muscle in response to chronic vasodilator treatment with alpha1-antagonist prazosin. Cell Tissue Res. 1087 293(2): 293-303.

1088

1089 
Figure Legends:

1091

Figure 1: Skeletal muscle capillary networks

1093

Skeletal muscle capillaries are oriented predominantly in parallel (arrows) with the long axis of muscle fibers (oriented left to right in this image). Interconnecting lateral branches (asterisks) and capillary loops (arrowheads) ensure thorough perfusion of the adjacent muscle fiber. To obtain this image, a mouse soleus muscle fiber bundle was fixed and stained using Griffonia simplificolia-fluorescein isothiocyanate to detect vascular endothelial cells. The capillary network was visualized on a Zeiss $200 \mathrm{M}$ microscope using a 10X objective and captured using a Z series stack, which was subsequently summed and processed by deconvolution (MetaMorph imaging software). The grayscale image was inverted to enhance visualization of the staining. The scale bar represents $50 \mu \mathrm{m}$.

Figure 2: Pro- and anti- angiogenic signals in response to aerobic exercise training

1104 Panels illustrate the major stimuli and cell signaling intermediaries associated with A) an acute bout of exercise; B) repeated bouts of exercise; and C) long term training that converge on endothelial cells to promote the induction of angiogenesis or capillary stabilization. Red font indicates activation or upregulation of a stimulus or factor within a time window of 0-4 hours post-exercise; gray font indicates no change or reduction in that factor. Please refer to the main text for details and relevant references. Coll XVIII- collagen XVIII; NO- nitric oxide;

1110 PGC1 $\alpha$ - peroxisome proliferator-activated receptor gamma, coactivator 1 alpha; HIF1 $\alpha$ - hypoxia 1111 inducible factor 1 alpha; Mdm2- murine double minute 2; MMP-2- matrix metalloproteinase-2; 1112 MMP-9 - matrix metalloproteinase-9; MMP-14 - matrix metalloproteinase 14; TIMP-1 - tissue 1113 inhibitor of matrix metalloproteinase-1; VEGF-A - vascular endothelial growth factor-A; VEGFR1 1114 -vascular endothelial growth factor receptor 1; VEGFR2-vascular endothelial growth factor 1115 receptor 2; ANGPT1 -angiopoeitin-1; ANGPT2 -angiopoeitin-2; Tie2 -tunica interna endothelial cell kinase 2; FoxO1/3- forkhead box 01/forkhead boxO3; THBS1 -thrombospondin-1. 


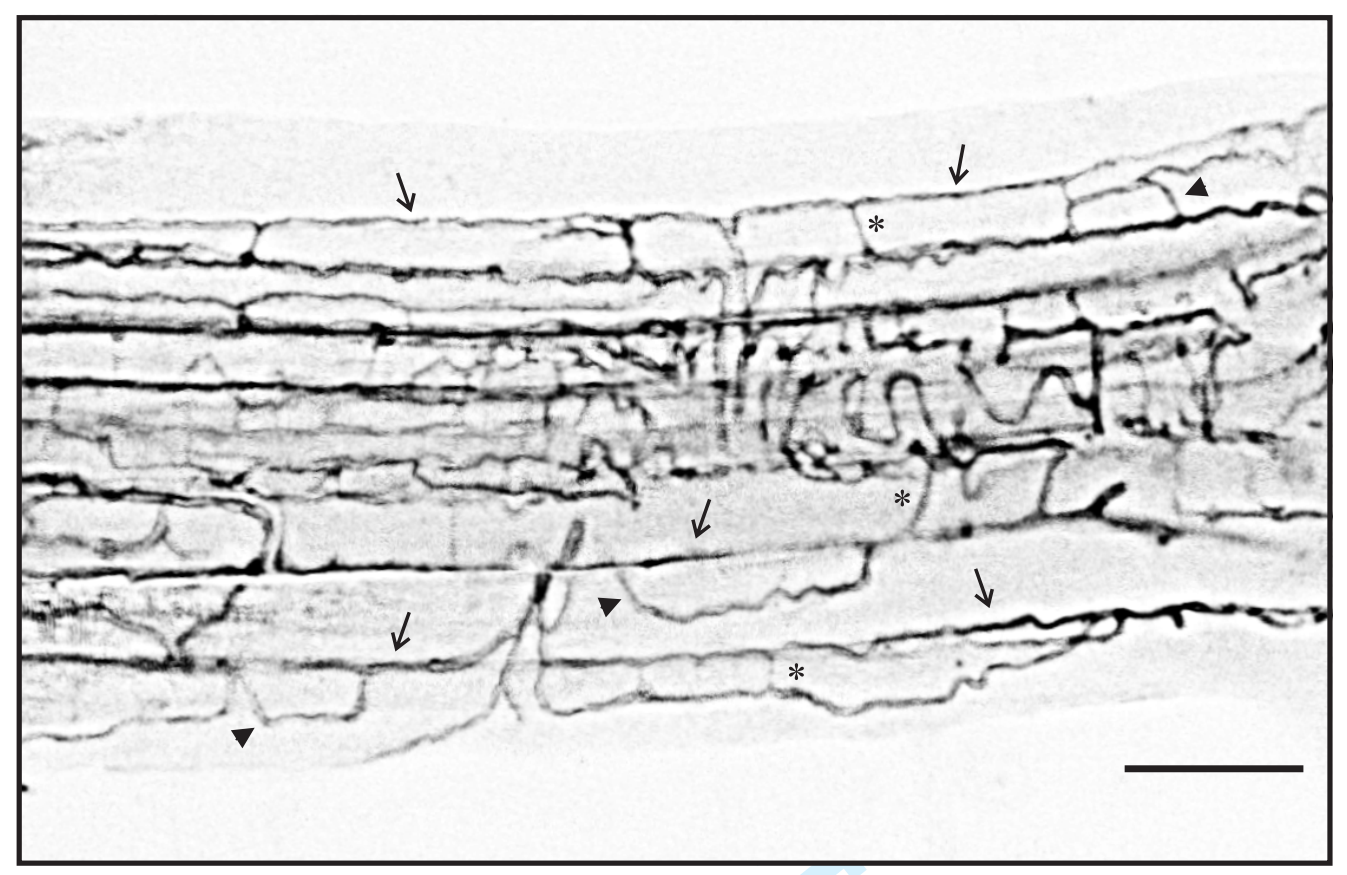

Fig. 1 
A

\section{ACUTE EXERCISE}

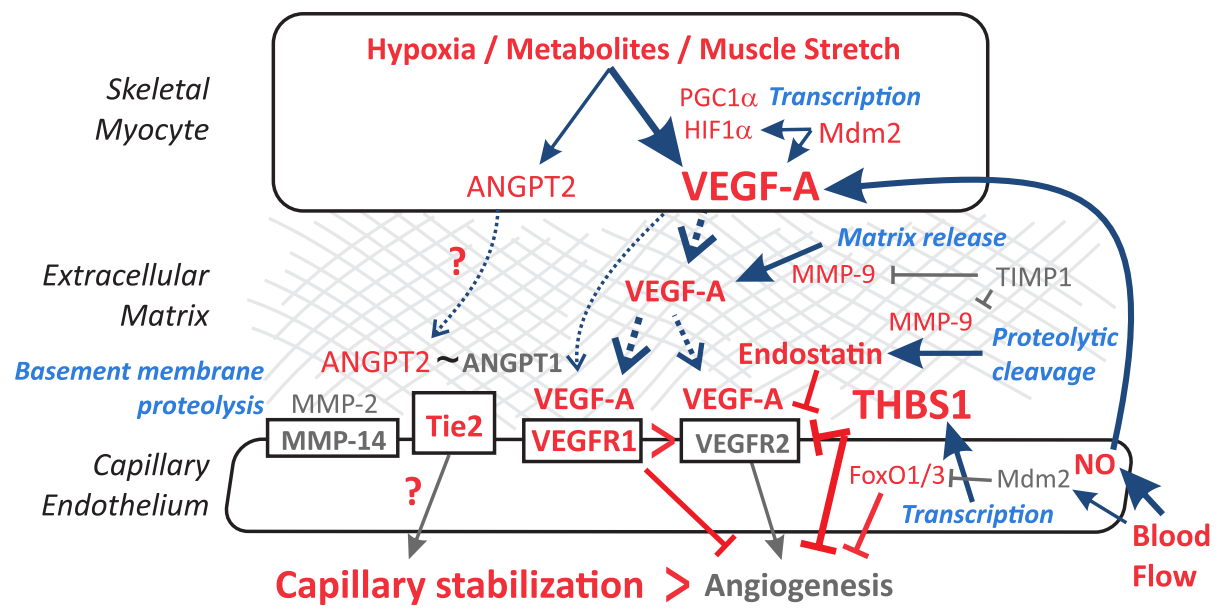

B

REPEATED EXERCISE

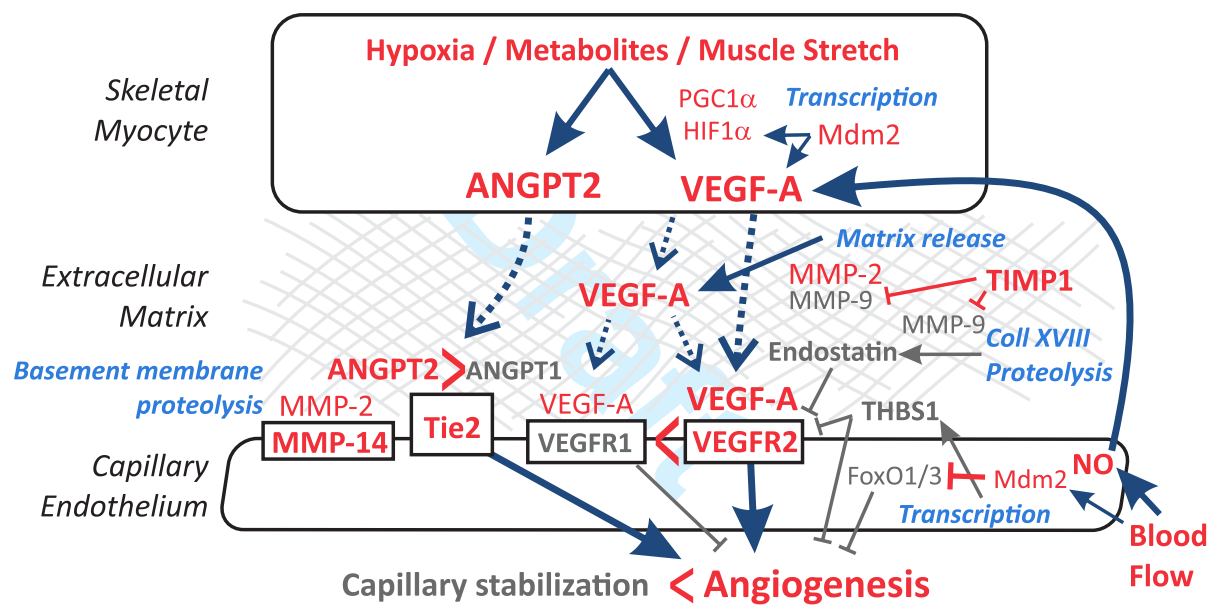

C

LONG TERM TRAINING

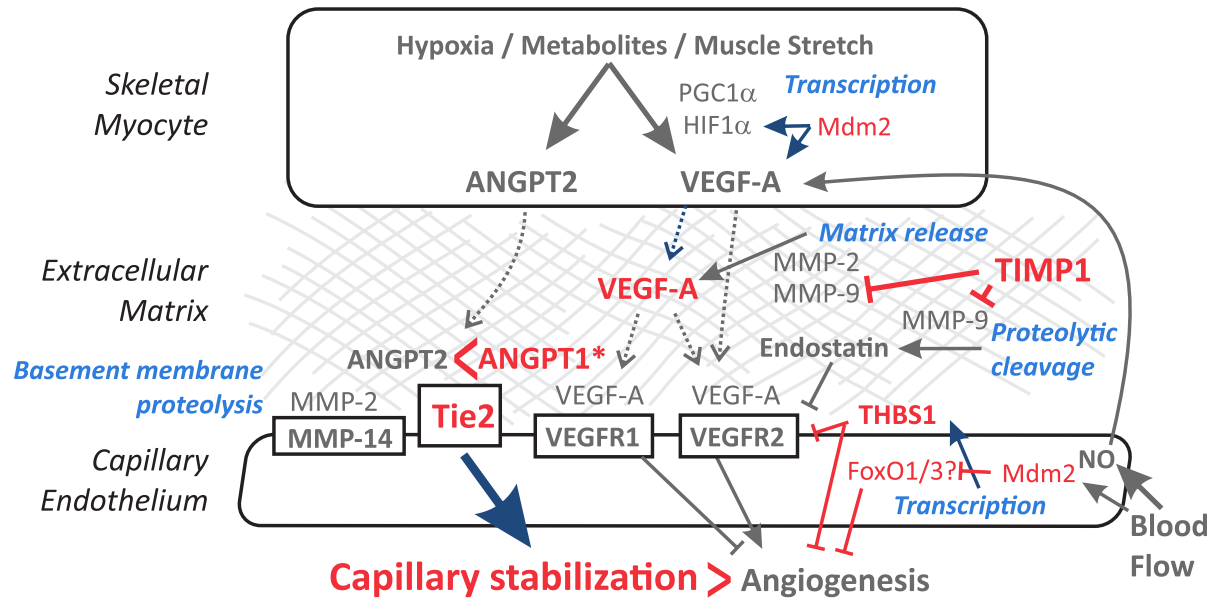

Fig. 2 